\title{
Transcriptome sequencing of human breast cancer reveals aberrant intronic transcription in amplicons and dysregulation of alternative splicing with major therapeutic implications
}

\author{
SHIVA SEYED FOROOTAN $^{1 *}$, JOE M. BUTLER $^{1 *}$, DEREK GARDENER $^{1}$, ALISON E. BAIRD $^{1}$, \\ ANDREW DODSON ${ }^{1}$, ALISTAIR DARBY ${ }^{2}$, JOHN KENNY ${ }^{2}$, NEIL HALL $^{2}$, ANDREW R. COSSINS $^{2}$, \\ CHRISTOPHER S. FOSTER ${ }^{1,3}$ and CHRISTINE M. GOSDEN ${ }^{1}$
}

\begin{abstract}
${ }^{1}$ Molecular Pathology Laboratory, Department of Molecular and Clinical Cancer Medicine, Institute of Translational Medicine, Faculty of Health and Life Sciences, University of Liverpool, Royal Liverpool University Hospital, Liverpool L69 3GA;

${ }^{2}$ Center for Genomic Research, University of Liverpool, Liverpool L69 7ZB; ${ }^{3} \mathrm{HCA}$ International, Pathology Laboratories, London WC1E 6JA, UK
\end{abstract}

Received June 30, 2015; Accepted July 31, 2015

DOI: $10.3892 /$ ijo.2015.3222

\begin{abstract}
Advances in genomic and transcriptome sequencing are revealing the massive scale of previously unrecognised alterations occurring during neoplastic transformation. Breast cancers are genetically and phenotypically heterogeneous. Each of the three major subtypes [ERBB2 amplified, estrogen receptor (ESR)-positive and triple-negative] poses diagnostic and therapeutic challenges. Here we show, using highresolution next-generation transcriptome sequencing, that in all three breast cancer subtypes, but not matched controls, there was significant overexpression of transcripts from intronic and untranslated regions in addition to exons from specific genes, particularly amplified oncogenes and hormone receptors. For key genes ERBB2 and ESR1, we demonstrate that overexpression is linked to the production of highly modified and truncated splice variants in tumours, but not controls, correlated with tumour subtype. Translation of these tumour-specific splice variants generates truncated proteins with altered subcellular locations and functions, modifying the phenotype, affecting tumour biology, and targeted antitumour therapies. In contrast, tumour suppressors TP53, BRCA1/2 and $N F 1$ did not show intronic overexpression or truncated splice variants in cancers. These findings emphasize the detection
\end{abstract}

Correspondence to: Dr Shiva Seyed Forootan, Molecular Pathology Laboratory, Department of Molecular and Clinical Cancer Medicine, Institute of Translational Medicine, Faculty of Health and Life Sciences, University of Liverpool, 5/6th floor, Duncan Building, Daulby Street, Liverpool, L69 3GA, UK

E-mail: shifor@liverpool.ac.uk

${ }^{*}$ Contributed equally

Key words: breast cancer, intronic transcription, splice variants, therapeutic target of intronic as well as exonic changes in the transcriptional landscapes of cancers have profound therapeutic implications.

\section{Introduction}

Breast cancer is the leading cause of cancer deaths in women. In the UK, between 1979 and 2011, the annual incidence of breast cancers increased from 23,876 to 49,936 (1) emphasizing the necessity to understand contemporary cancer biology to develop effective diagnosis and management. Of the three major subtypes, targeted therapies have been designed only for those with amplified ERBB2 and estrogen receptor-1 (ESRI) expression. The majority of breast cancers, including those involving familial $B R C A 1 / 2$ mutations, are not $E R B B 2$ amplified and are $E S R I$ and progesterone receptor $(P R)$-negative. For triplenegative breast cancers (TNC) (2-4) with five year survival rate of $77 \%$, compared with $93 \%$ for other subtypes $(5,6)$ treatment options are restricted to conventional chemotherapy.

Genomic alterations that define ERBB2 or ESR1 amplified breast cancer subtypes comprise massive oncogene or hormone receptor amplifications $(7,8)$ but not mutations or rearrangements in RefSeq exonic sequences. These are characterised by detection of amplification/overexpression, not genetic analysis of mutations or rearrangements revealed by exome sequencing (9-14). Recent demonstrations of the expression of novel (non-RefSeq) splice variants in cell lines (15-19), suggest amplification may not simply involve overexpression of exonic sequences alone but also non-exonic sequences. Furthermore, genome-wide association studies (GWAS) of single nucleotide polymorphisms (SNPs) in breast cancer indicate only $5 \%$ of high risk SNPs are exonic, the remaining 95\% localised to introns, UTRs and intergenic sequences suggesting that these intronic sequences may have functional roles (20-23). In this study next generation whole transcriptome sequencing has been employed to test the hypothesis that structural genomic changes occurring in human breast cancers are not random and stochastic but occur in combinations characteristic of specific sub-types and hence may predict phenotypic behaviour, including response to therapy. 


\section{Materials and methods}

Tissue samples and patient data. This study was approved by North West 12 Research Ethics Committee (Lancaster) in accordance with the Medical Research Council guidelines (project reference no. Gosden, 10/H1015/2). From 20 primary breast cancer specimens, frozen tissue sections were cut and stained with H\&E to assess morphology. Human breast tissues were obtained from Liverpool Tissue Bank as frozen tissues with the full record of the grade of carcinoma, age and hormonal status (ER, PR and HER2) of the samples (Table I).

RNA, DNA and protein extraction and quality assessment. Frozen tissues $(30 \mathrm{mg}$ ) from each of the 20 specimens were extracted using RLT buffer containing 2-ME (1 ml buffer and $10 \mu \mathrm{l}$ of $2-\mathrm{ME}$ ) added to the tissues following evaporation of liquid nitrogen.

After centrifugation, RNA, DNA and protein were extracted from the supernatant. The quantity of RNA and DNA was measured by NanoDrop (Labtech, Ringmer, UK). The quality of RNA for each sample was assessed by 2100 Bioanalyzer (Agilent Technologies, Santa Clara, CA, USA) using Agilent RNA 6000 Nano kit. The RNA integrity number (RIN) for all the samples was $>7.0$. The quality of DNA and protein was assessed using gel electrophoresis and Bradford assay, respectively.

Total RNA was further cleaned using the RiboMinus concentration modules (cat. no. K1550-05; Invitrogen) according to manufacturer's instructions. Depletion of rRNA from each sample was performed using the RiboMinus Eukaryote kit for RNA-Seq (cat. no. A1083708; Invitrogen) according to manufacturer's instructions. Successful removal of rRNA was confirmed using the Bioanalyzer.

cDNA library preparation and sequencing. Libraries of rRNA-depleted RNA suitable for sequencing using the SOLiD platform were created using the SOLiD Total RNA-Seq kit (part no. 4445374; Applied Biosystems). In each instance, $100 \mathrm{ng}$ of RNase III digested rRNA depleted RNA was used as input into the library creation and 15 cycles of amplification were employed to produce the final libraries. These libraries were sequenced on the SOLiD platform from Applied Biosystems. Initially sequencing of the 10 bp library barcode was performed followed by 35 and 50 bp pairedend sequencing. Fragments were subjected to paired-end sequencing using 35 and 50 bp reads.

Mapping ofRNA-Seqreads using TopHat. The sequenced pairedend tags were mapped to the reference human genome (hg19) using TopHat (24). This mapping approach ensures that a read, which spans an exon/exon boundary on the mRNA, is mapped to the genome such that it flanks the intervening intronic region (called junctions by TopHat). After alignment, two rounds of filtering were performed, the first to remove any low quality reads (mapping quality <10) and the second to remove any reads that mapped to ribosomal genes. Mappings were examined visually using SAMtools (25) and IGV (26). FPKM measures (gene expression quantified using the fragments per kilobase of exon per million reads mapped-FPKM) were calculated using the following definition: 'a fragment was counted if both paired end tags of the fragment F3 and F5 are observed or if only one of them (F3 or F5) is observed'. RefSeq co-ordinates were used to define exonic and intronic regions of the gene. Thus two FPKM values were calculated for each gene to measure exonic and intronic expression.

Genes were screened for differential exonic expression between a tumour sample and the paired normal tissue. Normal tissue samples were grouped together to calculate a standard deviation of the FPKM for each gene. A one-sampled t-test was applied for each gene, comparing its expression in a single cancer against the pooled normal tissue. Genes with low p-values indicated a high differential expression. The q-value package in $\mathrm{R}$ was applied to take account of multiple testing. The false discovery rate (FDR) was set to 0.001 . This was applied to each tumour sample to give a profile of the differentially expressed genes. Of the genes with significantly different exonic expression we distinguished whether they are up or down regulated in the tumour. This entire process was repeated to screen for genes with significant differential intronic expression.

In certain cancer specimens, significantly upregulated genes were clustered together at certain chromosomal locations. These were hypothesised to be the consequence of amplicons. The length of these amplicons was quantified using a method we devised that involves the minimization of a binomial probability. For a total of $X$ genes on a chromosome, then parameter $p$ is defined as $Y / X$ where $Y$ is the number of genes on that chromosome with significantly upregulated expression (intronic, exonic or both). Then, we consider $n$ consecutive genes encompassing the cluster, and count how many of those are significantly upregulated (intronic or exonic or both), let this number be $k$.

$$
f(k ; n, p)=\left(\begin{array}{l}
n \\
k
\end{array}\right) p^{k}(1-p)^{n-k}
$$

We calculate the binomial probability in the usual way with $n$ trials and $k$ successes. This is performed for different sets of consecutive genes encompassing the cluster; the set with the lowest binomial probability is chosen to represent the amplicon.

Validation of NGS by quantitative PCR (qPCR) and fluorescent in situ hybridization (FISH)

$q P C R$. For gene expression profiling, qPCR was used on a selection of upregulated or downregulated genes. The expression level was confirmed in ERBB2, ERBB3, VEGFA, FLT1, TP53, BRCA1, BRCA2, ESR 1 and PGR genes. The primers and amplicon size are addressed in Table II. The first strand cDNA was synthesized from 100-500 ng/ $\mu$ l total RNA using AffinityScript $^{\mathrm{TM}}$ multiple temperature cDNA synthesis kits (Stratagene, La Jolla, CA, USA) according to manufacturer's protocol. MX3305P real-time PCR machine (Stratagene) was used. Reaction volume was $10 \mu \mathrm{l}$ containing $5 \mu \mathrm{l}$ Brilliant SYBR-Green Master Mix (2X) (Stratagene), $1 \mu$ forward and reverse primers $(5 \mu \mathrm{M}), 1 \mu \mathrm{l}$ cDNA and $2 \mu \mathrm{l}$ water. Primers were all optimized for $60^{\circ} \mathrm{C}$. Cycling conditions were: $95^{\circ} \mathrm{C}$ for $15 \mathrm{~min}, 40$ cycles at $94^{\circ} \mathrm{C}$ for $15 \mathrm{sec}, 60^{\circ} \mathrm{C}$ for $30 \mathrm{sec}$, plate read and $72^{\circ} \mathrm{C}$ for $30 \mathrm{sec}$ with final extension of $72^{\circ} \mathrm{C}$ for $10 \mathrm{~min}$. Gene expression level was normalized relative to human $\beta$-actin expression. 
Table I. Clinical information for 20 breast tumours and paired normal controls, tumour grade, estrogen and progesterone receptor and ERBB2 (HER2) status.

\begin{tabular}{|c|c|c|c|c|c|c|}
\hline \multicolumn{2}{|c|}{$\begin{array}{l}\text { LTBRC no. tumour/ } \\
\text { control status }\end{array}$} & Age (years) & Grade & $\begin{array}{c}\text { Estrogen } \\
\text { receptor }(E S R 1)\end{array}$ & $\begin{array}{c}\text { Progesterone } \\
\text { receptor (PGR) }\end{array}$ & $\begin{array}{l}E R B B 2 \\
(H E R 2)\end{array}$ \\
\hline \multicolumn{7}{|c|}{ Tumour samples ERBB2 (Her2)-positive \pm estrogen receptor-positive } \\
\hline 1 & $221 \mathrm{~T}$ tumour & 53 & 3 & + & - & $3^{+}$ \\
\hline 2 & $\begin{array}{l}221 \mathrm{~N} \text { paired } \\
\text { control }\end{array}$ & & & & & \\
\hline 3 & $286 \mathrm{~T}$ & 76 & 3 & + & + & $3^{+}$ \\
\hline 4 & $326 \mathrm{~T}$ & 27 & 3 & + & + & $3^{+}$ \\
\hline 5 & $043 \mathrm{~T}$ & 84 & 3 & - & - & $3^{+}$ \\
\hline 6 & $121 \mathrm{~T}$ & 50 & 3 & + & - & $3^{+}$ \\
\hline 7 & $265 \mathrm{~T}$ & 48 & 2 & + & - & $2^{+}$ \\
\hline 8 & $193 \mathrm{~T}$ & 44 & 3 & - & - & $2^{+}$ \\
\hline \multicolumn{7}{|c|}{ Triple-negative samples (estrogen and progesterone receptor-negative and HER2-negative) } \\
\hline 9 & $194 \mathrm{~T}$ & 57 & 3 & - & - & - \\
\hline 10 & $271 \mathrm{~T}$ & 67 & 3 & - & - & - \\
\hline 11 & 013 tumour & 32 & 3 & - & - & - \\
\hline 12 & $013 \mathrm{~N}$ & Normal pair control & & & & \\
\hline 13 & $082 \mathrm{~T}$ & 37 & 3 & - & - & - \\
\hline 14 & $160 \mathrm{~T}$ & 69 & 3 & - & - & - \\
\hline 15 & $190 \mathrm{~T}$ & 77 & 3 & - & - & - \\
\hline 16 & $233 \mathrm{~T}$ & 61 & 3 & - & - & - \\
\hline 17 & $250 \mathrm{~T}$ & 67 & 3 & - & - & - \\
\hline 18 & $287 \mathrm{~T}$ & 55 & 3 & - & - & - \\
\hline 19 & $085 \mathrm{~T}$ & 86 & 3 & - & - & - \\
\hline 20 & $086 \mathrm{~T}$ & 50 & 3 & - & - & - \\
\hline 21 & 081 tumour & 43 & 3 & - & - & - \\
\hline 22 & $081 \mathrm{~N}$ control & Normal pair control & & & & \\
\hline 23 & 010 tumour & 34 & 3 & - & - & - \\
\hline 24 & $010 \mathrm{~N}$ control & Normal pair control & & & & \\
\hline
\end{tabular}

All breast cancers were invasive ductal carcinoma. The table shows the clinical information on the 12 breast tumours with the patient age, tumour stage and hormone receptor status for ESR1, PGR and ERBB2 (HER2). Tumours are designated with the suffix T and for tumours that have matched adjacent paired non-involved breast tissue these control samples have the same number but suffix $\mathrm{N}$.

FISH. FISH performed using the Kreatech ERBB2, Her2/SE17 probe kit (Kreatech) for detecting ERBB2 gene and ZytoLight SPEC ESRI/CEN 6 Dual Color Probe kit (Zytovision, Bremerhaven, Germany) for detecting ESRI gene, according to the manufacturer's instruction. Briefly, slides were deparafinized in xylene, incubated in heat pretreatment solution, EDTA buffer, using pressure cooker for $1 \mathrm{~min}$. Slides were incubated with proteinase $\mathrm{K}$ for $10 \mathrm{~min}$ at $37^{\circ} \mathrm{C}$ followed by wash with $\mathrm{dH}_{2} \mathrm{O}$ for $5 \mathrm{~min}$, dehydrated and air dried. Ten microliters of ZytoLight SPEC ESR 1/CEN 6 Dual Color Probe was applied to the slides in the dark followed by denaturation at $75^{\circ} \mathrm{C}$ for $10 \mathrm{~min}$ and overnight incubation at $37^{\circ} \mathrm{C}$ in the Hybrid OmniSlide hybridizer (Fisher Scientific). After hybridization, coverslips were removed using wash buffer (20X SSC and NP-40), washed at $72^{\circ} \mathrm{C}$ for $3 \mathrm{~min}$ in wash buffer and air dried in the dark. Subsequently, one drop of DAPI (Vector Laboratories) was applied to the slides and slides were covered with the coverslips. Slides were viewed and scored using the
Olympus BX61 cytovision fluorescence microscope. To calculate and record the results, the number of chromosome and gene signal was counted in 20-60 non-overlapping invasive cancer cell nuclei in 3 or more distinct fields. The gene to chromosome ratio was calculated. Gene amplification was defined as a ratio of $>2.2$. Values of 1.8-2.2 implied borderline amplification and below 1.8, not amplified.

Immunohistochemistry (IHC). Tissues were labelled with antibodies against p53 (clone DO-7; Dako), p63 (clone 4A4; NeoMarkers) and ESRI (clone 1D5; Dako) as previously described (27).

Western blotting. The protein level of $E R B B 2$ was evaluated with western blot analysis using two ERBB2 antibodies: mouse monoclonal antibody (ab16901) against 1242-1255 aa in C-terminus and rabbit polyclonal antibody (ab11717) (both from Abcam) against 651-660 aa. Western blotting was performed as described previously (27). The dilution of 
Table II. Primer sequence for qPCR identification and validation of NGS.

\begin{tabular}{|c|c|c|c|}
\hline Primer & Direction & Sequence & Amplicon size \\
\hline ERBB2 & $\begin{array}{l}\text { Forward } \\
\text { Reverse }\end{array}$ & $\begin{array}{l}\text { TGCTGGACATTGACGAGACAGAGT } \\
\text { AAGTCATCAGCTCCCACACAGTCA }\end{array}$ & 147 \\
\hline ERBB3 & $\begin{array}{l}\text { Forward } \\
\text { Reverse }\end{array}$ & $\begin{array}{l}\text { GAAAGTGTCAATGTGTAGGAGC } \\
\text { TCTTCTTCAGTACCCAGGACAG }\end{array}$ & 243 \\
\hline VEGFA & $\begin{array}{l}\text { Forward } \\
\text { Reverse }\end{array}$ & $\begin{array}{l}\text { CTACTGCCATCCAATCGAGAC } \\
\text { TCTTTCTTTGGTCTGCATTCAC }\end{array}$ & 255 \\
\hline FLT1 & $\begin{array}{l}\text { Forward } \\
\text { Reverse }\end{array}$ & $\begin{array}{l}\text { TGACACTTTGATCCCTGATGGA } \\
\text { ATGGCCTCTAAGTAATTTGACTGG }\end{array}$ & 217 \\
\hline TP53 & $\begin{array}{l}\text { Forward } \\
\text { Reverse }\end{array}$ & $\begin{array}{l}\text { GCCAAAGAAGAAACCACTGGA } \\
\text { TGGGCATCCTTGAGTTCCAA }\end{array}$ & 111 \\
\hline BRCA1 & $\begin{array}{l}\text { Forward } \\
\text { Reverse }\end{array}$ & $\begin{array}{l}\text { AGAAAGAGGAACGGGCTTGGAAGA } \\
\text { TGAGCAGTCTTCAGAGACGCTTGT }\end{array}$ & 115 \\
\hline BRCA2 & $\begin{array}{l}\text { Forward } \\
\text { Reverse }\end{array}$ & $\begin{array}{l}\text { TGAACTGACAGATTCTAAACTGCC } \\
\text { GGTTCTCCCACTAAGATAAGGG }\end{array}$ & 135 \\
\hline ESR1 & $\begin{array}{l}\text { Forward } \\
\text { Reverse }\end{array}$ & $\begin{array}{l}\text { TCACAGACACTTTGATCCACC } \\
\text { CAAGGAATGCGATGAAGTAGAG }\end{array}$ & 293 \\
\hline PGR & $\begin{array}{l}\text { Forward } \\
\text { Reverse }\end{array}$ & $\begin{array}{l}\text { ATTCCTTTGGAAGGGCTACGA } \\
\text { ATCCCTGCCAATATCTTGGGT }\end{array}$ & 284 \\
\hline$\beta$-actin & $\begin{array}{l}\text { Forward } \\
\text { Reverse }\end{array}$ & $\begin{array}{l}\text { AGCCTCGCCTTTGCCGA } \\
\text { CTGGTGCCTGGGGCG }\end{array}$ & 174 \\
\hline
\end{tabular}

antibodies are, 1/1,000 for polyclonal and 1/50 for monoclonal antibody. To confirm the presence of different splice variants, we employed PCR (FGFR2), IHC (p53) and western blotting $(E R B B 2)$. The presence of small numbers of mutations in our genes of interest such as p53 and BRCA2 was validated using Sanger sequencing.

\section{Results}

Deep transcriptome sequencing was undertaken in 20 primary breast cancer, including ERBB2-amplified, ESR1 amplified/overexpressed and triple-negative tumours and compared with matched morphologically non-neoplastic breast tissue controls. Analysis of the $3^{\prime}$ regions of AceView (Human 2010) variants of key breast cancer genes (ERBB2, TP53 and ESRI) revealed that 16/23, 12/17 and 4/8 respectively lacked poly(A) tails (data not shown). Whole transcriptome sequencing included exons, introns and UTRs to define gene expression in relation to breast cancer subtypes and across regions of interest including ERBB2 (chromosome 17), ESR1 (chromosome 6), $8 \mathrm{q} 24$ and $M Y C$ (chromosome 8) together with other oncogenes and tumour suppressor genes (TSG) including TP53/63/73, $B R C A 1 / 2, N F 1, C D K N 2 A / B$ implicated in breast cancer.

ERBB2 and detection of novel intronic tumour-specific transcript overexpression. ERBB2 an oncogenic receptor tyrosine kinase (RTK), is amplified in $\sim 20 \%$ of breast cancers (28). Of the 20 breast cancers examined, 5 contained ERBB2 amplification identified by FISH or IHC. The transcriptional consequences of $E R B B 2$ amplification were assessed using the FPKM measure defined as 'fragments per kilobase of exon per million reads mapped'. Stringent statistical analysis was employed to compare transcriptional expression in exons, introns, UTRs and overlaps on positive and negative strands in cancers with amplified and non-amplified ERBB2 and 835 genes covering the entire chromosome 17 in cancers of all three tumour sub-types and controls. Major differences were identified between the tumours with $E R B B 2$ amplification at 17q11.2-12 and matched controls for ERBB2 expression (Fig. 1). Those with ERBB2 amplification exhibited high levels of intronic as well as exonic expression, whereas all controls were negative. Intronic expression in tumours was not limited to $E R B B 2$. Detailed analysis of 835 genes located on whole chromosome 17 showed intronic tumour-specific sequence overexpression to occur 3.7 times more frequently than that for exons (Table III). Rigorous statistical analysis showed the mean intronic expression between tumours compared with controls was 48.7 (range, 1-208) (FDR 0.001 and >2-fold-change). The mean number of genes with FDR $<0.001$ exonic expression of the 835 genes on chromosome 17 in each of the tumour subtypes, was 12.7 (range, 0-41). Comparatively few genes had concurrent exonic and intronic expression, and for those genes with both exonic and intronic overexpression the mean was 5.1 (range, 0-32) (Table III).

To investigate whether intronic expression was specific to chromosome 17, or occurred in other breast tumours (including those with ESR1 amplification at $6 \mathrm{q} 25$ or $8 \mathrm{q} 24$ ), intronic and exonic gene expression was assessed for chromosomes 6 
Table III. Tumour rankings indicating significant exonic and intronic gene expression of 2120 genes of chromosomes 6,8 and 17 .

\begin{tabular}{|c|c|c|c|c|c|}
\hline & \multicolumn{4}{|c|}{ No. of genes with (exclusively) exonic significance } & \multirow[b]{2}{*}{ Rank } \\
\hline & $\begin{array}{c}\text { Chr } 6 \\
\text { (Total genes=797) } \\
\text { n }(\%)\end{array}$ & $\begin{array}{c}\text { Chr } 8 \\
(\text { Total genes=488) } \\
\text { n }(\%)\end{array}$ & $\begin{array}{c}\text { Chr } 17 \\
\text { (Total genes=835) } \\
\text { n }(\%)\end{array}$ & $\begin{array}{c}\text { Sum } \\
(\text { Total genes }=2120) \\
n(\%)\end{array}$ & \\
\hline $221 \mathrm{~T}$ & $4(0.50)$ & $17(3.48)$ & $6(0.72)$ & $27(1.27)$ & 5 \\
\hline $121 \mathrm{~T}$ & $1(1.13)$ & $4(0.82)$ & $4(0.48)$ & $9(0.42)$ & 7 \\
\hline $286 \mathrm{~T}$ & $32(4.02)$ & $41(8.40)$ & $41(4.91)$ & $114(5.38)$ & 1 \\
\hline $043 \mathrm{~T}$ & $11(1.38)$ & $18(3.69)$ & $14(1.68)$ & $43(2.03)$ & 4 \\
\hline $326 \mathrm{~T}$ & $0(0.00)$ & $1(0.20)$ & $2(0.24)$ & $3(0.14)$ & 9 \\
\hline $010 \mathrm{~T}$ & $6(0.75)$ & $1(0.20)$ & $0(0.00)$ & $7(0.33)$ & 8 \\
\hline $013 \mathrm{~T}$ & $36(4.52)$ & $24(4.92)$ & $41(4.91)$ & $101(4.76)$ & 3 \\
\hline $160 \mathrm{~T}$ & $16(2.01)$ & 87 (17.8) & $3(0.36)$ & $106(5.00)$ & 2 \\
\hline $081 \mathrm{~T}$ & $1(1.13)$ & $12(2.46)$ & $4(0.48)$ & $17(0.80)$ & 6 \\
\hline Mean & $11.9(1.58)$ & $22.8(4.66)$ & $12.8(1.53)$ & $47.5(2.24)$ & \\
\hline
\end{tabular}

\begin{tabular}{|c|c|c|c|c|c|}
\hline & \multicolumn{4}{|c|}{ No. of genes with (exclusively) intronic significance } & \multirow[b]{2}{*}{ Rank } \\
\hline & $\begin{array}{c}\text { Chr } 6 \\
(\text { Total genes=797) } \\
\text { n }(\%)\end{array}$ & $\begin{array}{c}\text { Chr } 8 \\
(\text { Total genes=488) } \\
\text { n }(\%)\end{array}$ & $\begin{array}{c}\text { Chr } 17 \\
\text { (Total genes=835) } \\
\text { n }(\%)\end{array}$ & $\begin{array}{c}\text { Sum } \\
(\text { Total genes }=2120) \\
\text { n }(\%)\end{array}$ & \\
\hline $221 \mathrm{~T}$ & $18(2.26)$ & $17(3.48)$ & $6(0.72)$ & $41(1.93)$ & 6 \\
\hline $121 \mathrm{~T}$ & $0(0.00)$ & $4(0.82)$ & $4(0.48)$ & $8(0.38)$ & 8 \\
\hline $286 \mathrm{~T}$ & $10(1.25)$ & $41(8.40)$ & $41(4.91)$ & $92(4.34)$ & 4 \\
\hline $043 \mathrm{~T}$ & $1(1.13)$ & $18(3.69)$ & $14(1.68)$ & $33(1.56)$ & 7 \\
\hline $326 \mathrm{~T}$ & $0(0.00)$ & $1(0.20)$ & $2(0.24)$ & $3(0.14)$ & 9 \\
\hline $010 \mathrm{~T}$ & $491(61.7)$ & $1(0.20)$ & $0(0.00)$ & $492(23.2)$ & 1 \\
\hline $013 \mathrm{~T}$ & $67(8.41)$ & $24(4.92)$ & $41(4.91)$ & $132(6.23)$ & 3 \\
\hline $160 \mathrm{~T}$ & $1(1.13)$ & $87(17.8)$ & $3(0.36)$ & $91(4.29)$ & 5 \\
\hline $081 \mathrm{~T}$ & $297(37.3)$ & $12(2.46)$ & $4(0.48)$ & $313(14.8)$ & 2 \\
\hline Mean & $98.3(12.58)$ & $22.8(4.66)$ & $12.8(1.53)$ & $133.9(6.32)$ & \\
\hline
\end{tabular}

\begin{tabular}{|c|c|c|c|c|c|}
\hline & \multicolumn{4}{|c|}{ No. of genes with both exonic and intronic significance } & \multirow[b]{2}{*}{ Rank } \\
\hline & $\begin{array}{c}\text { Chr } 6 \\
(\text { Total genes=797) } \\
\text { n }(\%)\end{array}$ & $\begin{array}{c}\text { Chr } 8 \\
(\text { Total genes=488) } \\
\text { n }(\%)\end{array}$ & $\begin{array}{c}\text { Chr } 17 \\
(\text { Total genes=835) } \\
\text { n }(\%)\end{array}$ & $\begin{array}{c}\text { Sum } \\
(\text { Total genes }=2120) \\
\text { n }(\%)\end{array}$ & \\
\hline $221 \mathrm{~T}$ & $0(0.00)$ & $49(10.0)$ & $32(3.83)$ & $81(3.82)$ & 2 \\
\hline $121 \mathrm{~T}$ & $0(0.00)$ & $0(0.00)$ & $13(1.56)$ & $13(0.61)$ & 7 \\
\hline $286 \mathrm{~T}$ & $9(1.13)$ & $25(5.12)$ & $0(0.00)$ & $34(1.60)$ & 6 \\
\hline $043 \mathrm{~T}$ & $2(0.25)$ & $0(0.00)$ & $0(0.00)$ & $2(0.09)$ & 8 \\
\hline $326 \mathrm{~T}$ & $0(0.00)$ & $0(0.00)$ & $0(0.00)$ & $0(0.00)$ & 9 \\
\hline $010 \mathrm{~T}$ & $25(3.14)$ & $11(2.25)$ & $0(0.00)$ & $36(1.70)$ & 5 \\
\hline $013 \mathrm{~T}$ & $24(3.01)$ & $25(5.12)$ & $0(0.00)$ & $49(2.31)$ & 3 \\
\hline $160 \mathrm{~T}$ & $5(0.63)$ & $98(20.1)$ & $0(0.00)$ & $93(4.86)$ & 1 \\
\hline $081 \mathrm{~T}$ & $14(1.76)$ & $28(5.74)$ & $1(0.12)$ & $43(2.03)$ & 4 \\
\hline Mean & $9.3(1.1)$ & $26.2(5.37)$ & $5.1(0.58)$ & 39 (1.89) & \\
\hline
\end{tabular}

The table shows the number of genes for each of the chromosomes 6,8 and 17 that have significant exonic, intronic or both exonic and intronic gene expression. The table indicates the findings for 797 genes of chr 6, 488 genes of chr 8 and 836 genes of chr 17 and from this derive the tumour rankings.

and 8 in each breast cancer subtype (Table III). Analysis of 2,119 genes spanning the whole of chromosomes 6,8 and 17 revealed $>2$-fold-changes for intronic and/or exonic expres- sion, in each of the different cancers and subtypes, but not controls (Table III). Intronic overexpression also occurred in TNCs and was not restricted to ERBB2 and ESRI amplified 

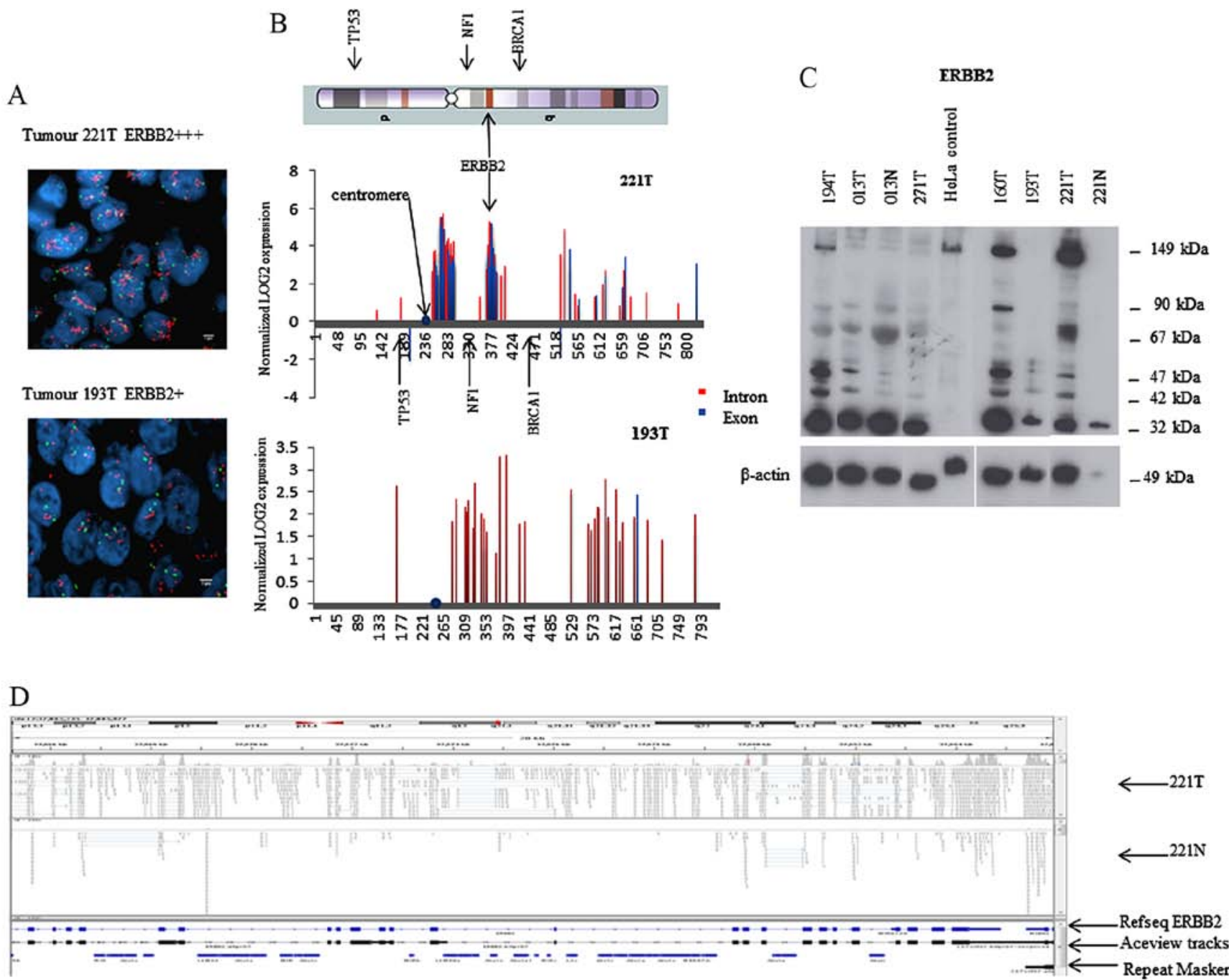

Figure 1. Transcriptional architecture of chromosome 17 in breast tumours; intronic overexpression in $E R B B 2$ and other genes, but not tumour suppressors p53, NF1 or BRCA1. (A) FISH of ERBB2 (red fluorescence) showing high level ERBB2 amplification in tumour 221T compared with non-amplified tumour 193T. Green fluorescent centromeric marker identifies chromosome copy number enabling calculation of $E R B B 2$ signals to chromosome number ( $>5: 1$ in $221 \mathrm{~T}$ vs. 1.5:1 for 193T) (magnification, x100). (B) Normalized Log2 expression (x-axis) for exonic (red) and intronic (blue) overexpression of 835 genes covering entire chromosome 17 (y-axis), demonstrating intense intronic overexpression in genes involved in 17q amplicons of tumour 221T, but not tumour $193 \mathrm{~T}$ without $17 \mathrm{q}$ amplification. Tumour $221 \mathrm{~T}$ has two $17 \mathrm{q}$ amplicons with high exonic and intronic overexpression in the pericentromeric amplicon [genes $261(N L K)$ to 302 (CRLF3)] and ERBB2 amplicon [375 (MED1) to 391 (CASC3)]; ERBB2 is at location 380. There was no overexpression of intronic sequences of tumour suppressors TP53 (at 143) or BRCA1 (455) in any tumours, not even for NF1 (at 302) located between the two 17q amplicons. (C) Western blot analyses showing the presence of multiple shorter protein isoforms of ERBB2 in breast tumours 194T, 013T, 271T, 160T, 193T and 221T compared with matched normal tissue controls $013 \mathrm{~N}$ and $221 \mathrm{~N}$. These result from translation of the multiple alternatively spliced transcripts of ERBB2 that include intronic and UTR sequences. HeLa cell control (lane 5) and $\beta$-actin used to normalise expression levels. Western blotting confirms truncated splice variant isoforms of $E R B B 2$ from alternatively spliced transcripts: $19 \mathrm{kDa}$ : variant a; $67 \mathrm{kDa}$ : variants $\mathrm{f}$ and g; $47 \mathrm{kDa}$ : variant $\mathrm{i}$; $42 \mathrm{kDa}$ : variant k, (AceView NCBI human 2010 nomenclature). (D) IGV snapshot demonstrating exonic and intronic expression of $E R B B 2$ occurs in tumour 221T, whereas paired normal breast control $221 \mathrm{~N}$, lacks intronic expression demonstrating intronic overexpression is tumour-specific.

tumours (Table III). There was overlap of transcripts between genes on the sense and antisense strands in the ERBB2 amplicon, but occurred only in tumours with $17 \mathrm{q}$ amplification. Paired end analysis of sequence overlap between ERBB2 and adjacent gene $C 17 O R F 37$ on the opposite strand revealed transcriptional overlaps between sense and antisense strands when alternatively spliced $E R B B 2$ and $C 17 O R F 37$ variants with longer 5' and 3'UTRs were expressed. These cancerspecific variants extended beyond normal RefSeq variants, creating sequence overlaps that did not occur in controls or tumours without ERBB2 amplification (Fig. 1). The amplicons and breakpoints involving ERBB2 at chromosome 17q11-12 were identified by stringent analysis of exonic and intronic expression of 835 genes on chromosome 17 in all three cancer subtypes and controls (Fig. 1).

$E R B B 2$ amplified tumours were characterised by $>2$-fold intronic and exonic overexpression of $E R B B 2$; neighbouring genes including $M E D 1, C D K 12$, STARD3, PGAP3, ERBB2, C17orf37, GRB 7, GSDMB, ORMDL3, PSMD3, MED24, MSL1 and $C A S C 3$ also showed intronic and exonic overexpression (Fig. 1). Most ERBB2 amplified tumours contained only one amplicon that included ERBB2 at 17q11.2-q12. However, two cancers contained both an ERBB2-amplicon and a second amplicon adjacent to the centromere (221T and 121T). Both amplicons were characterised by genes with $>2$-fold exonic and intronic expression. Between the two amplicons was a 


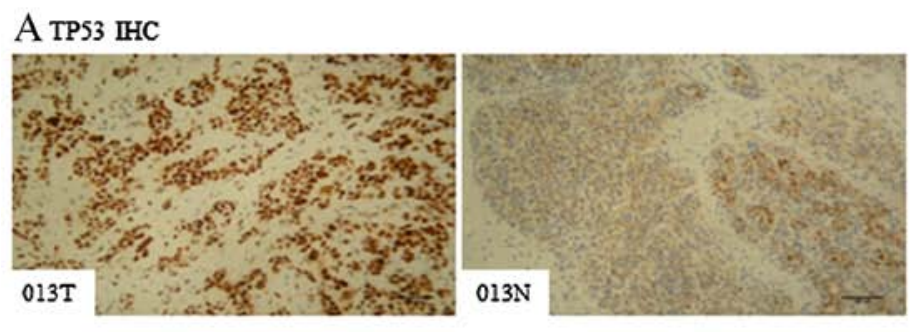

\section{B IGV TP53}

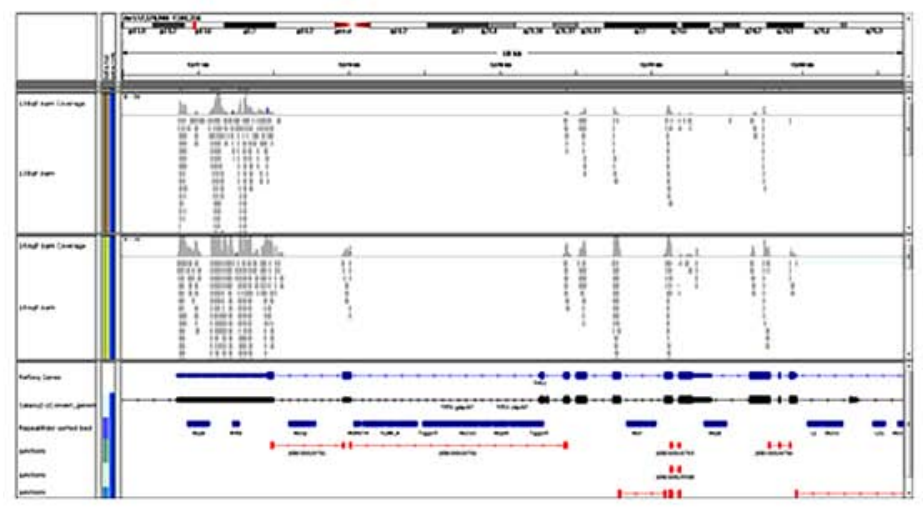

D IGV TP53 mutation

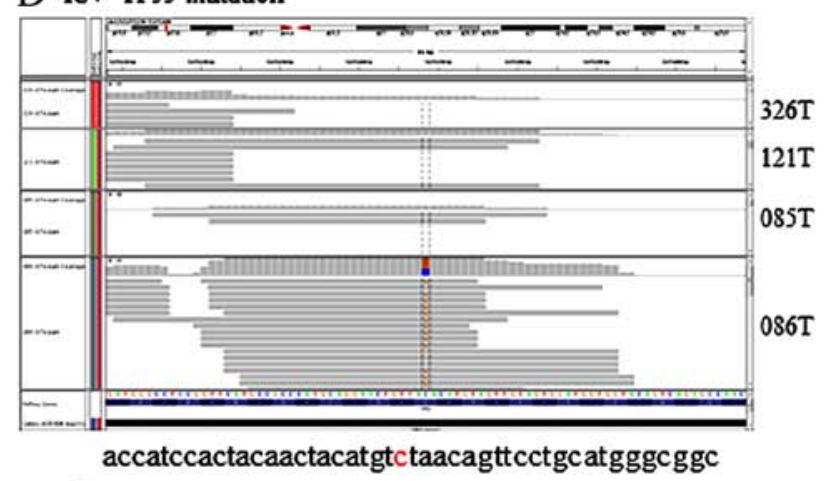

\section{E TP63 IHC}

$013 \mathrm{~N}$
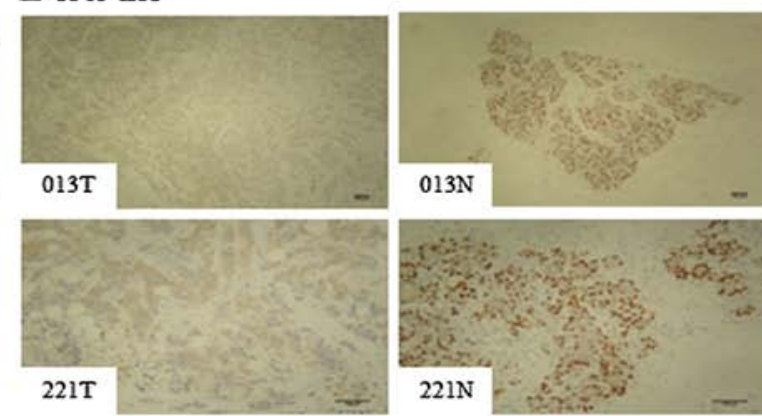

C TP53 exonic expression in $013 \mathrm{~T}$ and $013 \mathrm{~N}$

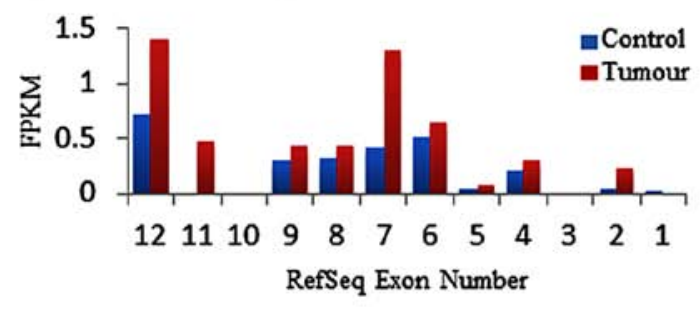

F

Exonic TP63 expression in 20 breast tumoursand 4 nomal control tissues (N, normal control; T, Tumour)

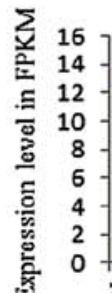

Figure 2. Tumour suppressor genes TP53, TP63 show no intronic overexpression in tumours; alternative splicing determines nuclear localisation. (A) Immunohistochemistry for TP53 demonstrating tumour 013T (x20) has nuclear localisation of TP53; in contrast, paired normal control 013N (x10) lacks nuclear localisation, is excluded from the nucleus and localised to the cytoplasm. (B) Nuclear localisation determined by alternatively splicing in TP53 and TP63. IGV screenshot shows TP53 in tumour 013T (lower panel) expressing of exon 11 encoding the nuclear localisation domain, thus conferring nuclear localisation for TP53 in tumour 013T. In contrast, paired normal control 013N (upper panel) does not express exon 11 and is thus excluded from the nucleus. Nuclear TP53 expression thus occurs only for tumour $013 \mathrm{~T}$ not the paired control $013 \mathrm{~N}$. This is confirmed by (A) IHC showing respective subcellular localisations of $013 \mathrm{~T}$ to nucleus and $013 \mathrm{~N}$ to cytoplasm. (C) Comparison of expression of each of the 12 individual exons of TP53 in tumour 013T in contrast to normal control $013 \mathrm{~N}$, showing exon 11 is expressed in tumour 013T but not in $013 \mathrm{~N}$ providing quantitative information in relation to (A) IHC and (B) IGV results. (D) TP53 transcriptome sequencing identifies mutations in transcripts: IGV demonstrates detection of mutation (C->G change) at position 7,577,568 chromosome 17 in tumour (lower panel), but not in control, (upper panel) confirmed by Sanger sequencing of TP53. (E) Immunohistochemistry of TP63 in tumour samples $013 \mathrm{~T}$ and $221 \mathrm{~T}$ in comparison with their paired normal control samples $013 \mathrm{~N}$ and $221 \mathrm{~N}$. This demonstrates greater expression in controls than the paired tumour samples, consistent with loss of TSG expression in tumourigenesis (013T and 013N, magnification, x10; 221T and 221N, magnification, x20). (F) Exonic TP63 expression levels in 20 breast tumour samples and 4 controls determined by FPKM analysis shows TP63 expression is significantly higher in controls than tumours $(\mathrm{p}<0.001)$.

non-amplified region in which none of the genes including the TSG, NF1 overexpressed or amplified (Fig. 1).

Tumour suppressor genes (TSG) including TP53, BRCA1/2 show no intronic overexpression in cancers. Our data revealed $17 \mathrm{q}$ amplification to be cancer-specific, occurring only in tumours but not matched controls (Fig. 1). The amplified $17 q$ amplicons varied in size, involved genes with elevated ( $>2$-fold) levels of intronic/exonic expression. Each individual amplicon comprised different breakpoints and genes, indicating a predisposition to amplicon formation in proximal $17 \mathrm{q}$, although this was not site-specific (Fig. 1). In contrast, none of the TSG on chromosome 17 (TP53 at 17p13, NF1 at 17q11.2), nor $B R C A 1$ at $17 \mathrm{q} 21$ showed $>2$-fold exonic or intronic expression in any tumour or control (Fig. 2). The most extreme case was that for the TSG and NF1 located in the region between the two chromosome 17q amplicons. Analysis of exonic and intronic expression in the two tumours with two 17q amplicons revealed that although genes proximal and distal to NF1 in the pericentromeric and ERBB2 amplicons showed $>2$-fold intronic or exonic overexpression, $N F 1$ was not overexpressed in any tumour or control. Mutation analysis, SNP expression, alternative splicing and subcellular localisation assessed for each of the three TSGs TP53, BRCA1 and NF1 located on 

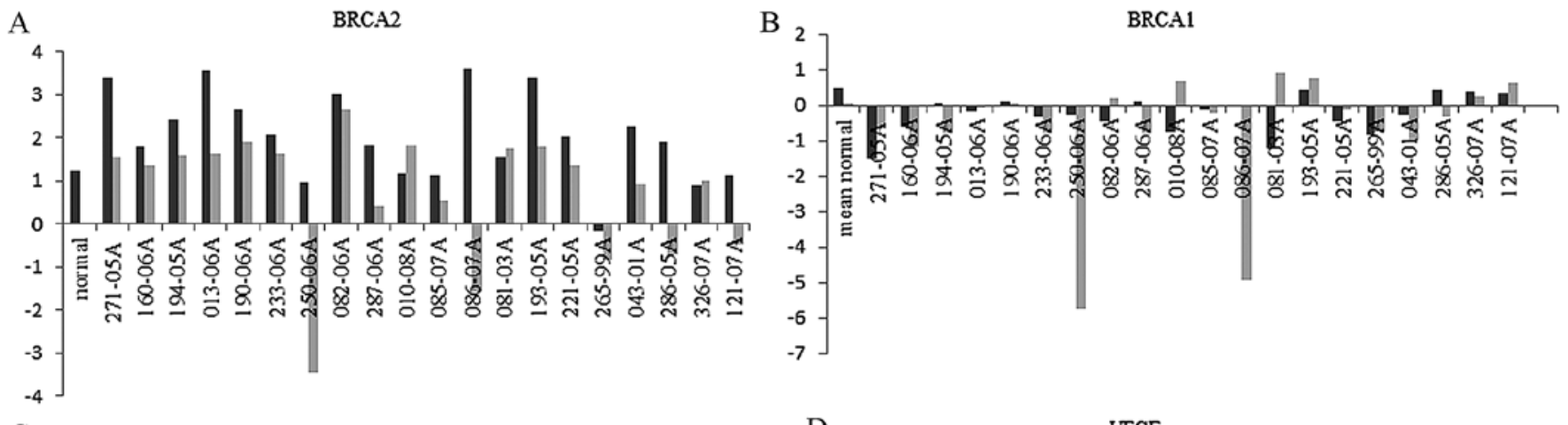

C
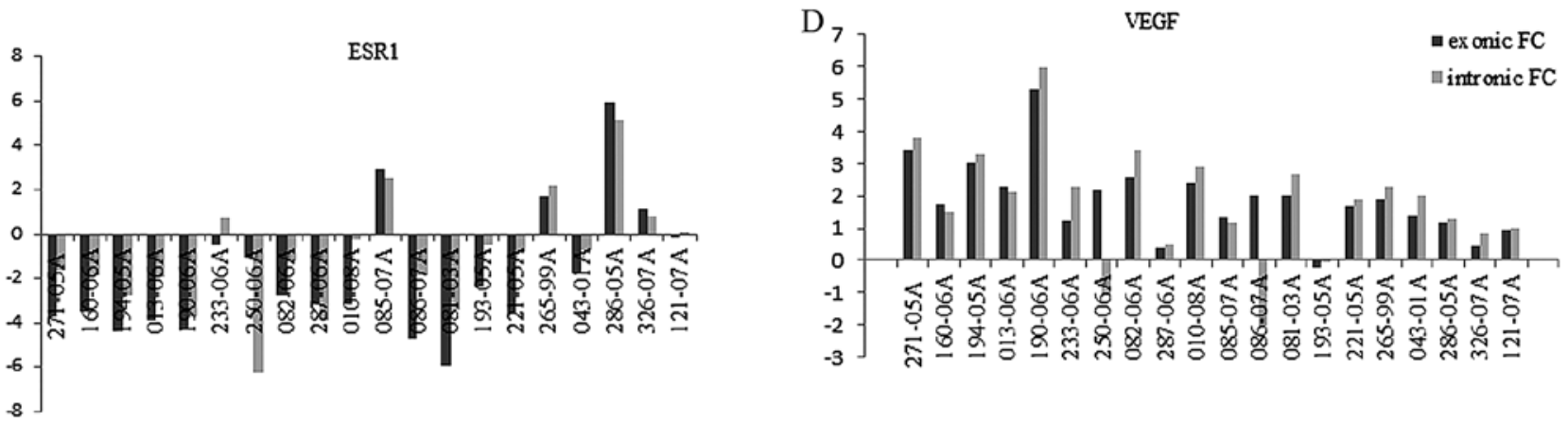

Figure 3. Exonic and intronic expression of four genes in 20 breast tumour samples and 4 controls determined by FPKM analysis. (A) BRCA2 exonic expression is significantly higher in 11/20 carcinomas compared to controls. Intronic expression level was higher in 15/20 cancers compare to normal and it was lower than control in 4/20 cancers. (B) BRCA1, the exonic expression level was lower than control in 19/20 tumours. The intronic expression level was higher in $6 / 20$ tumour compare to control. (C) ESR1 expression is significantly higher in $4 / 20$ and 5/20 for exonic and intronic expression respectively when normalized with controls. (D) The exonic and intronic VEGF expression is high in 19/20 and 17/20 tumours compare to control, respectively.

chromosome 17 (Fig. 2) revealed that alternative splicing of TP53 generated only 1-2 RefSeq splice variants. The findings for TP53,NF1 and BRCA1 reveal no $>2$-fold intronic or exonic expression and only RefSeq isoforms were detected in any tumour or control. This was consistent in other major TSGs including TP63/73, BRCA1/2, CDKN2A/2B and RB1/RBL1/ $R B L 2$ and it was in marked contrast to amplified oncogenes including ERBB2 and ESRI that generated multiple truncated tumour-specific isoforms. Using mutation analysis, a non-synonymous TP53 mutation was detected resulting in the amino acid change Cys106Ser in cancer 086T which was validated and confirmed using Sanger sequencing (Fig. 2). TP63 showed higher expression in controls than tumours, the expected pattern for TSGs (Fig. 2). TP63 expressed RefSeq variant $b$, an isoform with nuclear localisation and tetramerisation domains conferring nuclear localisation and confirmed by IHC (Fig. 2). TP73 was not expressed in these breast carcinomas.

In normal tissues, BRCA2 expression was significantly lower than in the malignant counterparts (Table IV and Fig. 3). Although no intronic or exonic expression $>2$-fold was found for $B R C A 2$, FPKM values were higher for exon 11, involved in DNA repair (29), than other exons. BRCAl, expression was significantly lower in $16 / 20$ carcinomas than the controls, with low intronic and exonic expression. Mutations were detected in $B R C A 2$, in contrast to $B R C A 1$ where no mutations were identified (Table IV). Thus a novel and important finding of this study is that TSGs express no more than two RefSeq splice variants in any cancer or control, in contrast to the multiple alternatively spliced transcripts in oncogenes and hormone receptors, suggesting that the transcriptional integrity of TSGs is tightly regulated in cancers, although this offers no protection against mutations or other changes.

Functional consequences of intronic overexpression: alternative splicing and truncated proteins. Transcriptome analyses for $E R B B 2$ were validated using $\mathrm{qPCR}$ to confirm transcript sequences, FISH to identify amplification, IHC to determine subcellular localisations and western blotting to confirm translation of alternatively spliced transcripts into proteins and assess the numbers and sizes of truncated protein isoforms in tumours and controls (Fig. 1). Several carcinomas expressed $>30$ copies of $E R B B 2$ when compared with matched controls and non-amplified tumours containing only two copies (Fig. 1). Chromosome 17 copy numbers in each cell were characterized using a concurrent second FISH probe to detect chromosome 17 centromeric sequences and hence identify chromosomal losses, gains and ploidy changes. In tumours with both $E R B B 2$ and pericentromeric amplicons, FISH revealed chromosome 17 centromeric regions in tumours to be larger than controls (Fig. 1), indicating amplification of the satellite and pericentromeric sequences, in agreement with studies demonstrating transcription of satellite, repeat, retrotransposon and other RNAs in tumourigenesis (30-33). We investigated intronic overexpression in relation to alternative splicing (AS) by calculating FPKM values for each exon, alternative exon and intron, aligning these with AceView (NCBI HG 19 Human AceView 2010) IGV and UCSC Blat. In carcinomas, when ERBB2 was amplified, multiple highly truncated alternatively spliced variants are transcribed, resulting in the expression of a larger proportion of the genome, particularly intronic sequences not 
A

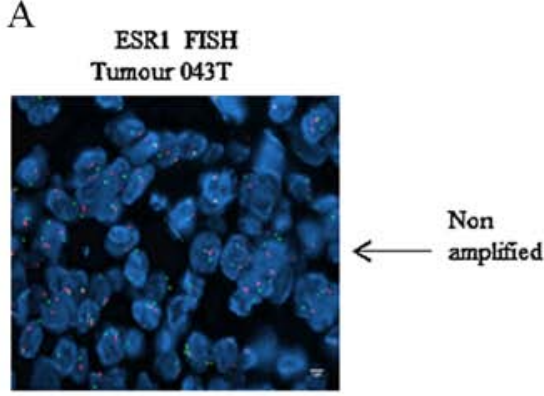

Tumour 286T

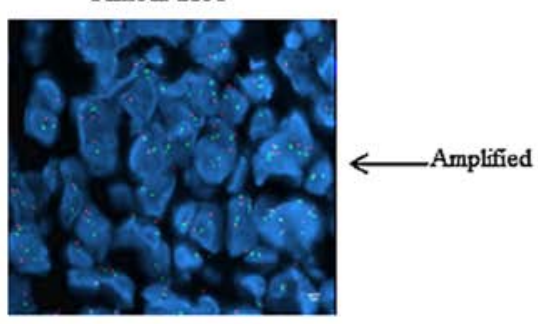

D

\begin{tabular}{|l|c|c|}
\hline Gene & $\begin{array}{c}\text { Exonic } \\
\text { FPKM } \\
\text { FC* }\end{array}$ & $\begin{array}{c}\text { Intronic } \\
\text { FPKM } \\
\text { FC* }\end{array}$ \\
\hline C6orf211 & 2.26 & 2.9 \\
\hline C6orf97 & 3.2 & 5.8 \\
\hline ESR1 & 5.9 & 5.1 \\
\hline
\end{tabular}

*Fold change compared to 4 controls
B

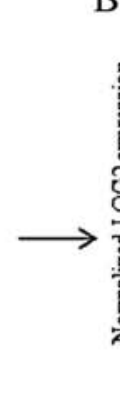

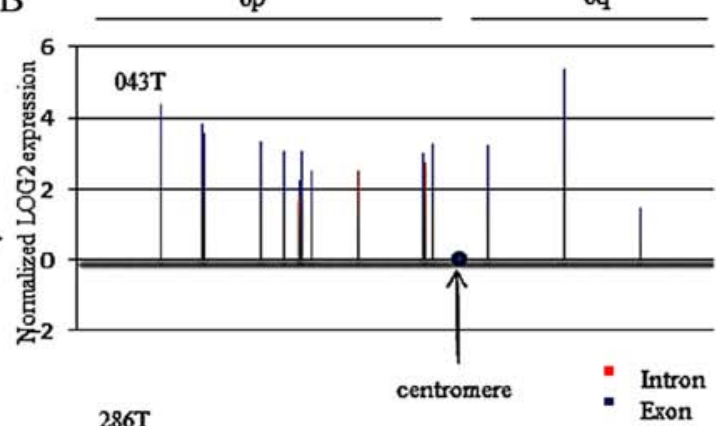

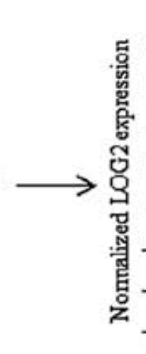

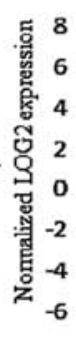

$286 \mathrm{~T}$

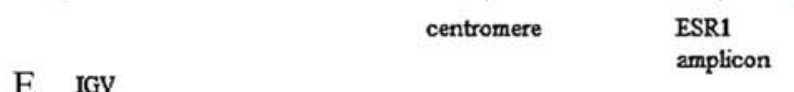

$\mathrm{C}$

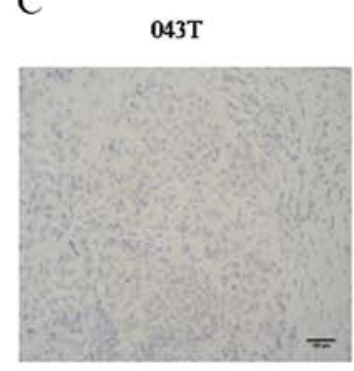

$286 \mathrm{~T}$

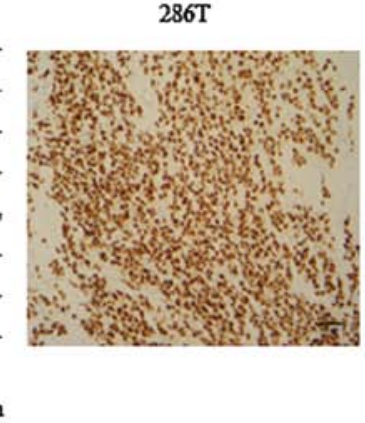

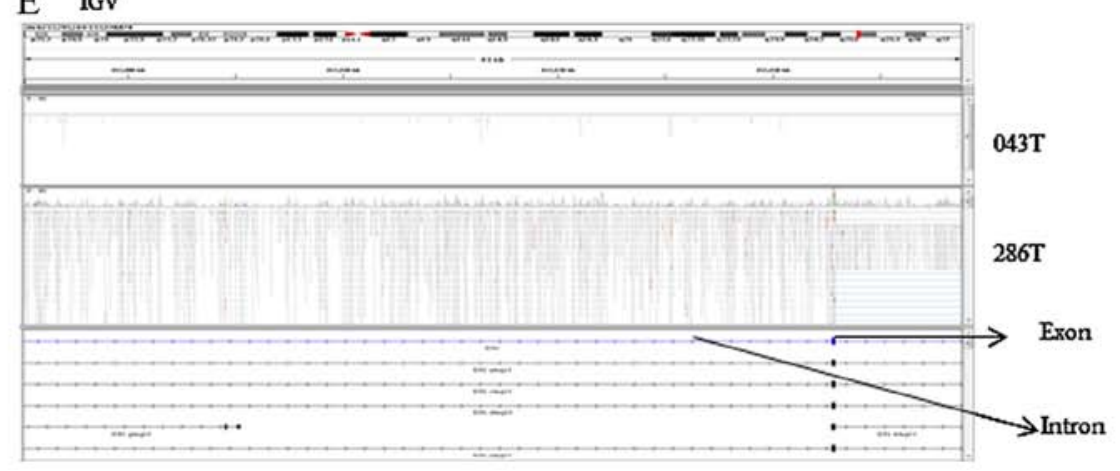

Figure 4. Tumour-specific amplification of hormone receptor ESR1 at chromosome $6 \mathrm{q} 26$ associated with intronic overexpression. (A) FISH analysis of ESRI in ESR1. Tumour sample 086T shows amplification of ESR1 by FISH analysis (ESR1 shown by fluorescent green signals) compared with non-amplified (043T) samples. Chromosome 6 centromeric probe (orange fluorescent signals) indicates the numbers of chromosome 6 present in relation to ESR1 signals (magnification, x100). (B) Normalized LOG2 expression of exons and introns over the 796 genes over the whole of chromosome 6, demonstrating the three genes, ESR1, C6ORF211 and C6ORF97 comprising the ESR1 amplicon at 6q26 in breast tumour 286T, but there is no ESR1 amplicon in the ESR1-negative sample 043T. (C) ESR1 immunohistochemistry demonstrates intense staining for ESR1 in the ESR1 amplified tumour 286T, compared with ESR1-negative tumour $043 \mathrm{~T}$ in line with the results for IHC and normalised LOG2 expression in (A and B). (D) Exonic and intronic FPKM fold-changes showing the very high levels of expression in the three genes ESR1, C6ORF97 and C6ORF211 that comprise the ESR1 amplicon in tumour 286T compared with pooled control samples. (E) IGV transcriptome screen shot demonstrating the specific high levels of exonic and intronic expression in ESRI (lower panel) in ESR1 amplified breast tumour 286T compared with the lack of intronic or expression in ESR-negative tumour 043T.

expressed in normal controls. The splice variants contained initiation sites, exons, introns, 5' and 3'UTRs, differing from the normal RefSeq variants of control samples, many being highly expressed. The transcriptional start and end points were validated using RT-PCR. To demonstrate that NMD pathways were not activated in these shortened transcripts, we used western blot analysis and subcellular localisation analysis to validate that in $E R B B 2$ amplified breast tumours, multiple alternatively spliced truncated transcripts were translated into highly truncated proteins, preponderantly smaller and varying in size, corresponding to the alternatively spliced $E R B B 2$ transcripts identified according to AceView (Fig. 1). In contrast, in normal breast and non-ERBB2 amplified tumours, the full length $E R B B 2$ isoform (149 $\mathrm{kDa}$ ) was predominant (Fig. 1).

ESR1, intronic transcription and overexpression affect function. Five of the 20 breast carcinomas expressed ESRl protein identified by IHC, although only three showed $>2$ exonic fold-change (Fig. 3). FPKM analysis of exonic and intronic expression of ESRI at 6q25 and a further 794 genes on chromosome 6 detected a small amplicon at $6 \mathrm{q} 25$ comprising the three genes ESR1, C6orf211 and C6orf9 in an ESR1-positive tumour sample, associated with both intronic and exonic overexpression in ESRI (Figs. 3 and 4). ESRI amplification was found to be associated with intronic overexpression and alternative splicing (Fig. 5). In the absence of estrogen, ESRI functions as a nuclear transcription factor that promotes breast cell growth. The receptors are inactive and cytoplasmic. However, on activation by estrogen, they dimerise and translocate to the nucleus. Thus, changes in subcellular localisation of ESR 1 from cytoplasm to the nucleus will effect its function.

We also analysed the transcriptional profiles of the other three major hormone receptors ESR2, progesterone receptor (PGR) and androgen receptor $(A R)$. For $P G R$, 
Table IV. Base pair changes in BRCA2 in all cases and base pair changes in the 8 repeats of BRCA2 gene.

A, Base pair changes in BRCA2 in all cases

\begin{tabular}{|c|c|c|c|c|}
\hline & Base pair change & Position & Syn/non syn & Rs \\
\hline & $\mathrm{GTA} \rightarrow \mathrm{GCA}$ & $32,929,387$ & Non syn (exon 14) & Rs169547 \\
\hline \multirow[t]{2}{*}{$193 \mathrm{~T}$} & ATAA $\rightarrow$ ATCA & $32,914,895$ & exon 11 & Rs80359583 \\
\hline & $\mathrm{CTG} \rightarrow \mathrm{CTC}$ & $32,915,005$ & Syn (exon 11) & Rs206076 \\
\hline \multirow[t]{3}{*}{$221 \mathrm{~T}$} & $\mathrm{GTA} \rightarrow \mathrm{GCA}$ & $32,929,387$ & Non syn (exon 14) & Rs169547 \\
\hline & ATAA $\rightarrow$ ATCA & $32,914,895$ & exon 11 & Rs80359583 \\
\hline & $\mathrm{CTG} \rightarrow \mathrm{CTC}$ & $32,915,005$ & Syn (exon 11) & Rs206076 \\
\hline \multirow[t]{2}{*}{$271 \mathrm{~T}$} & $\mathrm{GTA} \rightarrow \mathrm{GCA}$ & $32,929,387$ & Non syn (exon 14) & Rs169547 \\
\hline & $\mathrm{CTG} \rightarrow \mathrm{CTC}$ & $32,915,005$ & Syn (exon 11) & Rs206076 \\
\hline \multirow[t]{2}{*}{$194 \mathrm{~T}$} & $\mathrm{GTA} \rightarrow \mathrm{GCA}$ & $32,929,387$ & Non syn (exon 14) & Rs169547 \\
\hline & $\mathrm{CTG} \rightarrow \mathrm{CTC}$ & $32,915,005$ & Syn (exon 11) & Rs206076 \\
\hline \multirow[t]{3}{*}{$013 \mathrm{~T}$} & $\mathrm{GTA} \rightarrow \mathrm{GCA}$ & $32,929,387$ & Non syn (exon 14) & Rs169547 \\
\hline & $\mathrm{CAG} \rightarrow \mathrm{CAT}$ & $32,911,936$ & Non syn (exon 11) & - \\
\hline & $\mathrm{CTG} \rightarrow \mathrm{CTC}$ & $32,915,005$ & Syn (exon 11) & Rs206076 \\
\hline \multirow[t]{3}{*}{$190 \mathrm{~T}$} & $\mathrm{GTA} \rightarrow \mathrm{GCA}$ & $32,929,387$ & Non syn (exon 14) & Rs169547 \\
\hline & $\mathrm{CTG} \rightarrow \mathrm{CTC}$ & $32,915,005$ & Syn (exon 11) & Rs206076 \\
\hline & $\mathrm{G} \rightarrow \mathrm{T}$ & $32,890,572$ & 5' UTR & Rs1799943 \\
\hline \multirow[t]{3}{*}{$233 \mathrm{~T}$} & $\mathrm{GTA} \rightarrow \mathrm{GCA}$ & $32,929,387$ & Non syn (exon 14) & Rs169547 \\
\hline & $\mathrm{CTG} \rightarrow \mathrm{CTC}$ & $32,915,005$ & Syn (exon 11) & Rs206076 \\
\hline & $\mathrm{G} \rightarrow \mathrm{T}$ & $32,890,572$ & 5' UTR & Rs1799943 \\
\hline $250 \mathrm{~T}$ & $\mathrm{GTA} \rightarrow \mathrm{GCA}$ & $32,929,387$ & Non syn (exon 14) & Rs169547 \\
\hline \multirow[t]{3}{*}{$043 \mathrm{~T}$} & $\mathrm{GTA} \rightarrow \mathrm{GCA}$ & $32,929,387$ & Non syn (exon 14) & Rs169547 \\
\hline & $\mathrm{CTG} \rightarrow \mathrm{CTC}$ & $32,915,005$ & Syn (exon 11) & Rs206076 \\
\hline & $\mathrm{AAT} \rightarrow \mathrm{CAT}$ & $32,906,729$ & Non syn (exon 10) & - \\
\hline \multirow[t]{3}{*}{$286 \mathrm{~T}$} & $\mathrm{GTA} \rightarrow \mathrm{GCA}$ & $32,929,387$ & Non syn (exon 14) & Rs169547 \\
\hline & $\mathrm{CTG} \rightarrow \mathrm{CTC}$ & $32,915,005$ & Syn (exon 11) & Rs206076 \\
\hline & $\mathrm{AAT} \rightarrow \mathrm{CAT}$ & $32,906,729$ & Non syn (exon 10) & - \\
\hline \multirow[t]{2}{*}{$082 \mathrm{~T}$} & $\mathrm{GTA} \rightarrow \mathrm{GCA}$ & $32,929,387$ & Non syn (exon 14) & Rs169547 \\
\hline & $\mathrm{CTG} \rightarrow \mathrm{CTC}$ & $32,915,005$ & Syn (exon 11) & Rs206076 \\
\hline \multirow[t]{3}{*}{$287 \mathrm{~T}$} & $\mathrm{CTG} \rightarrow \mathrm{CTC}$ & $32,915,005$ & Syn (exon 11) & Rs206076 \\
\hline & $\mathrm{G} \rightarrow \mathrm{T}$ & $32,890,227$ & Intron 1 & Rs9567552 \\
\hline & $\mathrm{TCA} \rightarrow \mathrm{TCG}$ & $32,929,232$ & Syn (exon 14) & - \\
\hline $010 \mathrm{~T}$ & $\mathrm{GTA} \rightarrow \mathrm{GCA}$ & $32,929,387$ & Non syn (exon 14) & Rs169547 \\
\hline $085 \mathrm{~T}$ & $\mathrm{CTG} \rightarrow \mathrm{CTC}$ & $32,915,005$ & Syn (exon 11) & Rs206076 \\
\hline \multirow[t]{2}{*}{$086 \mathrm{~T}$} & $\mathrm{CTG} \rightarrow \mathrm{CTC}$ & $32,915,005$ & Syn (exon 11) & Rs206076 \\
\hline & $\mathrm{AAT} \rightarrow \mathrm{CAT}$ & $32,906,729$ & Non syn (exon 10) & - \\
\hline $081 \mathrm{~T}$ & $\mathrm{GTA} \rightarrow \mathrm{GCA}$ & $32,929,387$ & Non syn (exon 14) & Rs169547 \\
\hline
\end{tabular}

$\mathrm{B}$, Base pair changes in the 8 repeats of $B R C A 2$ gene

\begin{tabular}{lccc}
\hline & Base pair change & Position & Syn/non syn \\
\hline 193-05A & GUU $\rightarrow$ GUC & $32,912,299$ & SYN (V) \\
271-05A & AAA $\rightarrow$ AAG & $32,911,888$ & SYN (K) \\
013-06A & CAG $\rightarrow$ CAU & $32,911,936$ & NONSYN (Q $\rightarrow$ H) \\
233-06A & GUU $\rightarrow$ GUC & $32,912,299$ & SYN (V) \\
043-01A & GUU $\rightarrow$ GUC & $32,912,299$ & SYN (V) \\
286-05A & GAA $\rightarrow$ UAA & $32,914,118$ & NONSYN (E $\rightarrow$ STOP CODON) \\
287-06A & AAA $\rightarrow$ AAG & $32,911,888$ & SYN (K) \\
121-07A & AGU $\rightarrow$ AUU & $329,144,098$ & NONSYN (S $\rightarrow$ I) \\
081-03A & AAC $\rightarrow$ ACC & $32,911,932$ & NONSYN (N $\rightarrow$ T) \\
081-03B & GUU $\rightarrow$ GUC & $32,912,299$ & SYN (V) \\
\hline
\end{tabular}

The mutations and SNPs are shown with their genomic positions and details of whether these changes are synonymous or non-synonymous. 


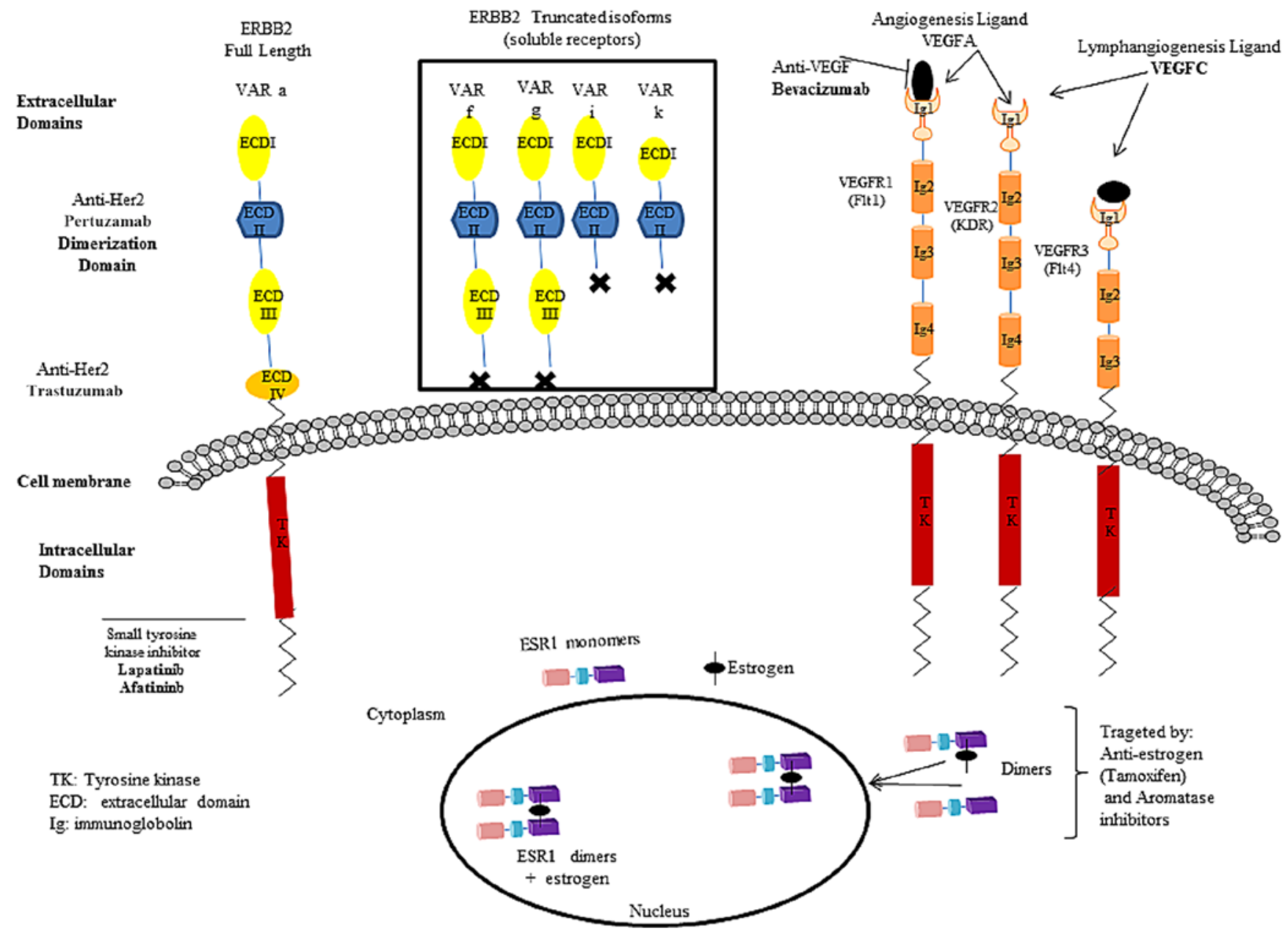

Figure 5. Schematic view of the consequences of tumour-specific intronic overexpression generating multiple alternatively spliced variants giving rise to short protein isoforms with altered structures, functions and subcellular localisations affecting targeted drug therapies. Figure shows a diagrammatic representation of a cell and its subcellular compartments with cell membrane, cytoplasm and nucleus. Upper left, full length RefSeq ERBB2 localised to cell membrane with extracellular domains targeted by monoclonal antibodies trastuzumab (Herceptin) and pertuzumab and intracellular TK domain targeted by small molecule tyrosine kinase inhibitors (lapatinib, erlotinib and gefitinib) indicated. The central box shows the shorter protein isoforms of $E R B B 2$ (variants $\mathrm{f}, \mathrm{g}$, i and k) identified by western blotting after exonic and intronic expression analysis and IGV. Unlike full length ERBB2 isoforms the short variants f, g, i and $\mathrm{k}$ lack ECD IV, the ECD targeted by Herceptin and intracellular TKI domains. These short isoforms also lack transmembrane and intracellular domains, resulting in 'soluble receptors' potentially carrying drugs into serum rather increasing levels in tumour cells. Upper right, multiple alternative splicing for angiogenic and lymphangiogenic receptors VEGFR1-3 (FLT1, KDR and FLT4, respectively) and their ligands VEGFA and VEGFC. As for the transmembrane receptor ERBB2, the generation of multiple proteins shorter than full length RefSeq forms may affect whether receptors and ligands such as VEGFA, are inhibitory, stimulatory and signal transduction. Lower figure monomers of $E S R I$ have cytoplasmic localisation but full length $E S R I$ is able to bind to estrogen allowing it to dimerise and move to the nucleus where it acts as a transcription factor. Our results (Fig. 4) demonstrate that tumours with amplified ESR1 or ESR1 intronic overexpression have only cytoplasmic, not nuclear ESR1 expression, which impairs its nuclear transcription factor function and responses to drug therapy.

18/20 cancers showed much lower exonic and intronic expression than the controls. The remaining 2 positive cancers were also positive by IHC. AR expression was negative in $12 / 20$ samples but positive in $8 / 20$. All 12 samples negative for $A R$ were triple-negative subtypes.

Oncogene expression in amplicons: $8 q 24$ amplification without MYC overexpression. The $8 \mathrm{q} 24$ region is frequently amplified in breast cancers and may be associated with MYC oncogene overexpression (34). In a tumour with 8q24 amplification, we studied intronic and exonic expression in 488 genes over the whole of chromosome 8 , comparing tumours in each of the three subtypes with controls. Many genes contained exonic or intronic overexpression (Table III). Surprisingly, no exonic or intronic overexpression ( $>2$-fold) was detected for $M Y C$ in the $8 \mathrm{q} 24$ amplified tumour. This finding was striking, because the adjacent gene, MTSS1 (at 8p22), showed $>2$-fold exonic and intronic expression of 4.1 and 3.7, respectively, whereas MYC did not (Table III and Fig. 4). It was assumed axiomatic that 8q24 amplification would involve $M Y C$ overexpression. However, our studies show that although $2.5 \%$ (range, $0.2-17.8 \%$ ) of the 488 genes on chromosome 8 demonstrated exonic overexpression, $15.4 \%$ (range, $0-24.8 \%$ ) intronic overexpression and $5.4 \%$ (range, $0-20.1 \%$ ) both exonic and intronic overexpression, MYC showed no overexpression. To further characterise oncogene expression, we investigated whether overexpression occurred for other oncogenes including $E G F R$ family members ( $E G F R, E R B B 3$ and $E R B B 4$ ) in each tumour subgroup and controls. No tumour or control showed $E G F R$ amplification. For $E R B B 3$, one sample with overexpressed $E R B B 2$ (286T) showed a $>2$-fold-change of both exonic and intronic expressions. For ERBB4, two ERBB2 $3^{+}$patients 
Table V. Mutations, SNPs and base pair changes in VEGFA gene.

\begin{tabular}{|c|c|c|c|c|}
\hline & Base pair change & Position & Syn/non syn & Rs \\
\hline 271T, 190T, 10T, 10B & $A \rightarrow G$ & $43,753,212$ & 3'UTR & Rs10434 \\
\hline 043T, 085T, 086T, 081T & $\mathrm{TCC} \rightarrow \mathrm{TCT}$ & $43,738,977$ & & Rs 25648 \\
\hline 082T, 010T, 265T & $\begin{array}{l}\mathrm{C} \rightarrow \mathrm{T} \\
\mathrm{CTG} \rightarrow \mathrm{CTC}\end{array}$ & $43,746,169$ & Intron 3 & Rs3025000 \\
\hline $081 \mathrm{~T}$ & $\begin{array}{l}\mathrm{ATG} \rightarrow \mathrm{AGC} \\
\mathrm{G} \rightarrow \mathrm{T}\end{array}$ & $\begin{array}{l}43,738,985 \\
43,752,287\end{array}$ & $3^{\prime}$ exon & \\
\hline $086 \mathrm{~T}$ & $\mathrm{G} \rightarrow \mathrm{A}$ & $43,753,325$ & 3'UTR & Rs3025023 \\
\hline $\begin{array}{l}250 \mathrm{~T}, 286 \mathrm{~T}, 082 \mathrm{~T}, 043 \mathrm{~T}, \\
326 \mathrm{~T}, 121 \mathrm{~T}, 085 \mathrm{~T}, 086 \mathrm{~T} \\
010 \mathrm{~T}, 081 \mathrm{~T}, 265 \mathrm{~T}, 190 \mathrm{~T}, \\
\text { 233T, 287T }\end{array}$ & $\mathrm{G} \rightarrow \mathrm{T}$ & $43,746,276$ & Intron 4 & Unknown \\
\hline $221 \mathrm{~T}, 286 \mathrm{~T}$ & $\mathrm{C} \rightarrow \mathrm{T}$ & $43,752,536$ & 3'UTR & Rs3025039 \\
\hline $221 \mathrm{~T}, 194 \mathrm{~T}$ & $\mathrm{C} \rightarrow \mathrm{T}$ & $43,753,051$ & 3'UTR & Rs3025040 \\
\hline
\end{tabular}

showed $>2$-fold-changes (221T entrance and 286T exonic) and one triple-negative patient $(085 \mathrm{~T})$ showed $>2$-fold exonic and intronic overexpression. Other major oncogene families investigated included epidermal, fibroblast, vascular endothelial and platelet derived growth factor receptors.

Specificity of intronic transcription and alternatively spliced transcripts. To investigate whether intronic overexpression was associated with particular introns and sequences, we calculated FPKM values for each exon, alternative exon and intron. We aligned these with the AceView alternative splicing database, using IGV, UCSC Blat and Repeat Masker to identify locations of repeat sequences, retrotransposons and other repeat elements (NCBI HG19 UCSC Blat, IGV and Repeat Masker). The upregulated intronic sequence expression found in cancers was not random, with high specificity for genes, introns and sequences involved associated with retrotransposons and other repeat sequences (data not shown). For $E R B B 2$, the two introns with highest FPKM values were those immediately before the transmembrane domain. Predictions indicated that these would give rise to shorter, alternatively spliced variants and truncated protein isoforms lacking transmembrane and intracellular domains, no longer localised to the cell membrane, and instead generating soluble receptors (Fig. 5). Intronic LINES, Alus and other retroelements (enigmatic dark matter) can induce alternative splicing by mechanisms including exonisation of cryptic splice sites, forcing exonisation and cryptic polyadenylation or exon skipping (35-39). In this way, intronic or intergenic sequence expression may contribute to the acquisition of new exons and alternatively spliced variants.

TNCs, intronic overexpression and identification of drug targets. We confirmed that TNCs contained no ERBB2 or ESR1 amplification, but for TNCs our results demonstrate that for VEGFA, 10/13 exhibited >2-fold exonic or intronic expression, but 3/13 (23\%) showed no overexpression, emphasising the need for personalised profiling to increase effectiveness and reduce toxicity (Figs. 3 and 5). VEGFA undergoes alternative splicing, producing variants having either stimulatory or inhibitory functions (40), highlighting that transcriptome profiling may enable targeting of stimulatory isoforms. We have also shown a number of synonymous or non-synonymous mutation in VEGFA (Table V). In this study, TNC produced only inhibitory isoforms. VEGF receptors are also potential therapeutic targets, but our results showed no significant elevated expression for VEGFR1 (FLT1) or VEGFR2 (KDR) (Fig. 5).

Tumour-specific transcription, alternative splicing, protein isoforms and targeted cancer therapies. For ERBB2 amplified tumours, intronic overexpression, multiple alternatively spliced transcripts and protein isoforms of tumours differ markedly from those of non-malignant samples and have implications for diagnosis, prognosis, targeted therapies and biomarkers. Although full length RefSeq ERBB2 found in normal cells is localised to cell membrane, in tumours, truncated $E R B B 2$ isoforms have differing sizes, and subcellular localisations. Some isoforms may lack transmembrane and intracellular domains and no longer localise to cell membrane, becoming soluble receptors, but still have extracellular domains that bind to targeted drugs, forming soluble-receptor drug complexes, potentially partitioning toxic drug-soluble receptor complexes into serum (Fig. 5). Oncogenic proteins with altered or ablated drug target domains with altered monoclonal antibody or TK inhibitor binding, may render therapies ineffective or tumours unresponsive (Figs. 1 and 5). The estrogen receptor ESR1 normally localises to the nucleus, functioning as a nuclear transcription factor. However, our results demonstrate that ESR 1 amplification may result in cytoplasmic rather than nuclear localisation, affecting nuclear transcription factor function (Figs. 3 and 5). The results suggest transcription of intronic 'dark matter' in cancers plays a key role in generating novel transcriptional landscapes, that provides insights into tumour biology and potential pitfalls and new opportunities for personalised cancer therapies (41). 


\section{Discussion}

Functional implications of tumour-specific intronic transcription and alternative splicing. This study revealed the extent of genomic structural alterations occurring during the evolution of human breast cancers and has identified some of the key changes to be subtype-specific and mutually exclusive. The findings have fundamental implications for tumourspecific breast cancer therapy. In non-neoplastic cells, $\sim 2-3 \%$ of genomic 'exonic' DNA primes synthesis of protein-coding mRNA and transcription is tightly regulated (42). Here, we show that in cancers, massive genomic rearrangements occur with pervasive cancer-specific transcriptional changes that include intronic sequence overexpression generating alternatively spliced transcripts and truncated protein isoforms cannot be revealed by exome analysis. First, RefSeq exome sequencing cannot detect intronic overexpression and tumour-specific alternative splicing. Second, the relevance of these findings to current breast cancer treatment is that they show the functional correlates of tumour-specific alterations, revealing new biologically relevant therapeutic targets. Third, alternatively spliced tumour-specific transcripts and truncated proteins are likely to alter drug target domains. These structural changes within the genome modify the therapeutic effectiveness of targeted drugs such as Herceptin (trastuzumab) or small molecule TK inhibitors, designed to target external or TK domains of full length RefSeq ERBB2 (43). Truncation may ablate or alter drug target domains and explain lack of response, ineffectiveness or resistance to targeted therapies. Finally, GWAS have identified genetic risk loci for breast cancers and SNPs are a key resource in cancer genetics. However, many high-risk SNPs are intronic, suggesting the functional involvement of intronic sequences in cancers. More than $95 \%$ of breast cancer susceptibility variants are found in non-exonic regions previously thought to be non-coding. Our studies provide a framework for tumour-specific analysis of introns and other non-exonic regions to assess whether high risk SNPs may be associated with tumour-specific transcription.

Massive genomic rearrangements, oncogenes and tumour suppressors in breast cancer. The data herein suggested that some chromosomal regions including 17q, 6q and 8q24 appear predisposed to amplicon formation. However, each amplicon has differing breakpoints, indicating the uniqueness and complexities of individual amplicon formation. Relationships between chromosomal amplification and oncogene overexpression may also be complex. Prior to these studies, it appeared axiomatic that $8 \mathrm{q} 24$ amplification inevitably involved $M Y C$ overexpression. However, for 8q24 amplification and MYC our data show that oncogene overexpression and chromosomal amplification are not invariably linked. Absence of $M Y C$ overexpression in 8q24 amplification was surprising given that $15.4 \%$ of chromosome 8 genes showed intronic overexpression, $2.5 \%$, showed exonic overexpression and $5.4 \%$ exhibited both. The findings illustrate the necessity for detailed gene expression studies to analyse functional correlates of chromosome amplification, rather than relying solely on surrogates such as FISH.

In contrast to oncogene/hormone receptor amplification and intronic overexpression, no TSG showed intronic or exonic overexpression or the generation of truncated alternatively spliced variants. The comparisons were stark, given that in some tumours, TSGs including BRCAl and NFl were located immediately adjacent to $17 \mathrm{q}$ amplicons in which oncogenes including ERBB2 showed extensive intronic overexpression, alternative splicing and generated truncated protein isoforms. The expression profiles of TSGs suggest that, by their resistance to transcriptional disruption and intronic overexpression, these genes retain their normal function and highlight the abnormalities and extent of tumour-specific changes in amplified oncogenes. TSGs play key roles to prevent tumourigenesis in breast and other epithelia. The implications of our findings are that in tumours there are either mechanisms leading to intronic sequences overexpression and triggering tumour specific alternative splicing or mechanisms that prevent transcription of intronic sequences, in TSGs even when closely mapping oncogenes are amplified and overexpressed. Suggestions that mutations in TP53 may be linked with catastrophic chromosomal tumour-specific amplifications and rearrangements are intriguing and bring new perspectives in relation to TSGs and mechanisms of amplification (44). Analysis of TP53 mutations in relation to $17 \mathrm{q}, 6 \mathrm{q}$ and $8 \mathrm{p}$ amplification revealed no direct links between TP53 mutations and amplicons, although other loci, amplicons and mutations in other types of tumour should be analysed.

The human genome contains $40-50 \%$ of repetitive sequences derived from retrotransposable elements, with multiple copies of long and short interspersed nucleotide elements (LINES and SINES), LTRs and other repeat sequences $(31,45-47)$. This study provides additional new information about the extent of intronic transcription and alternative splicing that illuminates the accumulating evidence in cancer, transcription of intronic, UTR satellite and transposon sequences occurs and extends the repertoire of alternatively spliced transcripts (31). Intronic L1s, Alus and other retroelements (enigmatic dark matter) affect transcription and gene expression via exon skipping and exonisation using cryptic splice sites, forcing exonisation and cryptic polyadenylation so genes acquire new exons from intronic or intergenic sequences thereby generating novel alternatively spliced variants $(41,48)$. Recently, we described intronic exonisation in human prostate cancer, suggesting that this phenomenon is likely to be common to many different malignancies (49). In normal somatic cells, this sequence compartment is attenuated by epigenetic silencing mechanisms involving DNA methylation and chromatin-mediated repression to maintain genomic integrity $(45,50,51)$. In tumours, there are suggestions that transcription from retrotransposons occurs subsequent to loss of methylation (50). Loss or inactivation of TSGs in cancers, has led to the suggestion that demethylating agents may be utilised to promote expression of lost or inactivated TSGs. While demethylating drugs may enhance TSG expression, there are potential risks of exacerbating or increasing retrotransposon transcription, that may potentially result in oncogene or other tumour promoting gene upregulation or overexpression, accelerating tumourigenesis rather than suppressing growth (52).

Effects of tumour-specific transcription and translation on targeted cancer therapies. In this study, we demonstrate that intronic regions harbour sequences transcribed only in 
cancers and not in normal tissues. Since such tumour-specific sequences encompass transcripts not included in RefSeq exons or revealed by exome analysis, studies should be extended beyond the limits of individual exomes if the full extent of cancer transcription and exploitation of intronic and intergenic sequences is to be uncovered. Such previously unrecognised transcription and translation from amplified or disrupted oncogenes will generate RNA transcripts and proteins with altered size structures, functions and subcellular localisations similar to those detected in prostate cancer (49). Drug development has been predicated on targeting normal full-length RefSeq proteins with domains such as external, transmembrane and TK domains in RTKs. Divergent protein isoforms could potentially affect function through diverse mechanisms ranging from ablation of drug target domains to alterations such as those to soluble rather than transmembrane receptors for RTKs $(53,54)$, nuclear transcription factors localised to the cytoplasm for ESRl (55), mesenchymal rather than epithelial signalling for $F R G R 2(56,57)$ and inhibitory rather than stimulatory functions for VEGFA (58). For amplified ERBB2 these findings have major implications for targeted therapies.

Despite the promise of personalized cancer medicine, therapeutic options are available only for breast cancers with amplified/overexpressed ERBB2 or ESR1. TNCs are the most aggressive tumours but lack therapeutic options, having no targetable ERBB2 or ESR1 overexpression. Our findings suggest transcriptome profiling may identify alternative physiological mechanisms as therapeutic targets. Non-selective genome-wide demethylation is unlikely to be therapeutically advantageous while anti-angiogenic therapies may be ineffective, or potentially toxic, without therapeutic benefit, thus explaining the disappointing results of the anti$V E G F A$ monoclonal bevacizumab and FDA withdrawal of approval for use in breast cancer (FDA 2011). This study suggests transcriptional profiling may be an appropriate approach to individual cancers by providing a comprehensive identification of new therapeutic targets for effective personalised cancer therapies.

\section{References}

1. Office for National Statistics: Office for National Statistics, Cancer Statistics Registrations: Registrations of Cancer Diagnosed in 2008, England. Series MB1. National Statistics, London, p43, 2012.

2. Sorlie T, Tibshirani R, Parker J, Hastie T, Marron JS, Nobel A, Deng S, Johnsen H, Pesich R, Geisler S, et al: Repeated observation of breast tumor subtypes in independent gene expression data sets. Proc Natl Acad Sci USA 100: 8418-8423, 2003.

3. Baldassarre G, Battista S, Belletti B, Thakur S, Pentimalli F, Trapasso F, Fedele M, Pierantoni G, Croce CM and Fusco A: Negative regulation of BRCA1 gene expression by HMGA1 proteins accounts for the reduced BRCA1 protein levels in sporadic breast carcinoma. Mol Cell Biol 23: 2225-2238, 2003.

4. O'Shaughnessy J, Osborne C, Pippen JE, Yoffe M, Patt D, Rocha C, Koo IC, Sherman BM and Bradley C: Iniparib plus chemotherapy in metastatic triple-negative breast cancer. $\mathrm{N}$ Engl J Med 364: 205-214, 2011.

5. Dent R, Hanna WM, Trudeau M, Rawlinson E, Sun P and Narod SA: Pattern of metastatic spread in triple-negative breast cancer. Breast Cancer Res Treat 115: 423-428, 2009.

6. Rodríguez-Pinilla SM, Sarrió D, Honrado E, Hardisson D, Calero F, Benitez J and Palacios J: Prognostic significance of basal-like phenotype and fascin expression in node-negative invasive breast carcinomas. Clin Cancer Res 12: 1533-1539, 2006.
7. Hicks J, Krasnitz A, Lakshmi B, Navin NE, Riggs M, Leibu E, Esposito D, Alexander J, Troge J, Grubor V, et al: Novel patterns of genome rearrangement and their association with survival in breast cancer. Genome Res 16: 1465-1479, 2006.

8. Ficz G, Branco MR, Seisenberger S, Santos F, Krueger F, Hore TA, Marques CJ, Andrews S and Reik W: Dynamic regulation of 5-hydroxymethylcytosine in mouse ES cells and during differentiation. Nature 473: 398-402, 2011.

9. Hudis CA: Trastuzumab - mechanism of action and use in clinical practice. N Engl J Med 357: 39-51, 2007.

10. Giampaglia M, Chiuri VE, Tinelli A, De Laurentiis M, Silvestris $\mathrm{N}$ and Lorusso V: Lapatinib in breast cancer: Clinical experiences and future perspectives. Cancer Treat Rev 36 (Suppl 3): S72-S79, 2010.

11. Folkman J: Angiogenesis: An organizing principle for drug discovery? Nat Rev Drug Discov 6: 273-286, 2007

12. Carey LA and Sharpless NE: PARP and cancer - if it's broke, don't fix it. N Engl J Med 364: 277-279, 2011.

13. Leslie M: Brothers in arms against cancer. Science 331: 1551-1552, 2011.

14. Tao Y, Liu S, Briones V, Geiman TM and Muegge K: Treatment of breast cancer cells with DNA demethylating agents leads to a release of Pol II stalling at genes with DNA-hypermethylated regions upstream of TSS. Nucleic Acids Res 39: 9508-9520, 2011.

15. Jones S, Zhang X, Parsons DW, Lin JC, Leary RJ, Angenendt P, Mankoo P, Carter H, Kamiyama H, Jimeno A, et al: Core signaling pathways in human pancreatic cancers revealed by global genomic analyses. Science 321: 1801-1806, 2008.

16. Sugarbaker DJ, Richards WG, Gordon GJ, Dong L, De Rienzo A, Maulik G, Glickman JN, Chirieac LR, Hartman ML, Taillon BE, et al: Transcriptome sequencing of malignant pleural mesothelioma tumors. Proc Natl Acad Sci USA 105: 3521-3526, 2008.

17. Bueno R, De Rienzo A, Dong L, Gordon GJ, Hercus CF, Richards WG, Jensen RV, Anwar A, Maulik G, Chirieac LR, et al: Second generation sequencing of the mesothelioma tumor genome. PLoS One 5: e10612, 2010.

18. Chen W, Kalscheuer V, Tzschach A, Menzel C, Ullmann R, Schulz MH, Erdogan F, Li N, Kijas Z, Arkesteijn G, et al: Mapping translocation breakpoints by next-generation sequencing. Genome Res 18: 1143-1149, 2008.

19. Rothberg JM and Leamon JH: The development and impact of 454 sequencing. Nat Biotechnol 26: 1117-1124, 2008.

20. Kwan T, Benovoy D, Dias C, Gurd S, Provencher C, Beaulieu P, Hudson TJ, Sladek R and Majewski J: Genome-wide analysis of transcript isoform variation in humans. Nat Genet 40: 225-231, 2008.

21. Lee YH, Kim JH and Song GG: Genome-wide pathway analysis of breast cancer. Tumour Biol 35: 7699-7705, 2014.

22. Hajiloo M, Damavandi B, Hooshsadat M, Sangi F, Mackey JR, Cass CE, Greiner R and Damaraju S: Breast cancer prediction using genome wide single nucleotide polymorphism data. BMC Bioinformatics 14 (Suppl 13): S3, 2013.

23. Gascard P, Bilenky M, Sigaroudinia M, Zhao J, Li L, Carles A, Delaney A, Tam A, Kamoh B, Cho S, et al: Epigenetic and transcriptional determinants of the human breast. Nat Commun 6: 6351,2015

24. Trapnell C, Pachter L and Salzberg SL: TopHat: Discovering splice junctions with RNA-Seq. Bioinformatics 25: 1105-1111, 2009.

25. Li H, Handsaker B, Wysoker A, Fennell T, Ruan J, Homer N, Marth G, Abecasis G and Durbin R; 1000 Genome Project Data Processing Subgroup: The Sequence Alignment/Map format and SAMtools. Bioinformatics 25: 2078-2079, 2009.

26. Robinson JT, Thorvaldsdóttir H, Winckler W, Guttman M, Lander ES, Getz G and Mesirov JP: Integrative genomics viewer. Nat Biotechnol 29: 24-26, 2011.

27. Forootan SS, Wong YC, Dodson A, Wang X, Lin K, Smith PH, Foster CS and Ke Y: Increased Id-1 expression is significantly associated with poor survival of patients with prostate cancer. Hum Pathol 38: 1321-1329, 2007

28. Ro JS, el-Naggar A, Ro JY, Blick M, Frye D, Fraschini G, Fritsche $\mathrm{H}$ and Hortobagyi G: c-erbB-2 amplification in nodenegative human breast cancer. Cancer Res 49: 6941-6944, 1989.

29. Jensen RB, Carreira A and Kowalczykowski SC: Purified human BRCA2 stimulates RAD51-mediated recombination. Nature 467: 678-683, 2010.

30. Faulkner GJ, Kimura Y, Daub CO, Wani S, Plessy C, Irvine KM, Schroder K, Cloonan N, Steptoe AL, Lassmann T, et al: The regulated retrotransposon transcriptome of mammalian cells. Nat Genet 41: 563-571, 2009. 
31. Faulkner GJ: Retrotransposons: Mobile and mutagenic from conception to death. FEBS Lett 585: 1589-1594, 2011.

32. Parenteau J, Durand M, Morin G, Gagnon J, Lucier JF, Wellinger RJ, Chabot B and Elela SA: Introns within ribosomal protein genes regulate the production and function of yeast ribosomes. Cell 147: 320-331, 2011.

33. Baillie JK, Barnett MW, Upton KR, Gerhardt DJ, Richmond TA, De Sapio F, Brennan PM, Rizzu P, Smith S, Fell M, et al: Somatic retrotransposition alters the genetic landscape of the human brain. Nature 479: 534-537, 2011.

34. Xu J, Chen Y and Olopade OI: MYC and Breast Cancer. Genes Cancer 1: 629-640, 2010.

35. Pennisi E: Shining a light on the genome's 'dark matter'. Science 330: 1614, 2010.

36. Gal-Mark N, Schwartz S and Ast G: Alternative splicing of Alu exons - two arms are better than one. Nucleic Acids Res 36: 2012-2023, 2008.

37. Bennett EA, Keller H, Mills RE, Schmidt S, Moran JV, Weichenrieder O and Devine SE: Active Alu retrotransposons in the human genome. Genome Res 18: 1875-1883, 2008.

38. Hormozdiari F, Alkan C, Ventura M, Hajirasouliha I, Malig M, Hach F, Yorukoglu D, Dao P, Bakhshi M, Sahinalp SC, et al: Alu repeat discovery and characterization within human genomes. Genome Res 21: 840-849, 2011.

39. Bazak L, Levanon EY and Eisenberg E: Genome-wide analysis of Alu editability. Nucleic Acids Res 42: 6876-6884, 2014.

40. Bates DO, Cui TG, Doughty JM, Winkler M, Sugiono M, Shields JD, Peat D, Gillatt D and Harper SJ: VEGF165b, an inhibitory splice variant of vascular endothelial growth factor, is down-regulated in renal cell carcinoma. Cancer Res 62: 4123-4131, 2002.

41. Blaxter M: Genetics. Revealing the dark matter of the genome Science 330: 1758-1759, 2010.

42. Alberts B, Johnson A, Roberts K, Raff M, Lewis J and Bray D: Molecular Biology of the Cell. Garlang Publishing, Inc., New York, 1983.

43. Jackson C, Browell D, Gautrey H and Tyson-Capper A: Clinical significance of HER-2 splice variants in breast cancer progression and drug resistance. Int J Cell Biol 2013: 973584, 2013.

44. Rausch T, Jones DT, Zapatka M, Stütz AM, Zichner T, Weischenfeldt J, Jäger N, Remke M, Shih D, Northcott PA, et al: Genome sequencing of pediatric medulloblastoma links catastrophic DNA rearrangements with TP53 mutations. Cell 148 59-71, 2012.

45. Goodier JL and Kazazian HH Jr: Retrotransposons revisited: The restraint and rehabilitation of parasites. Cell 135: 23-35, 2008.
46. Häsler J and Strub K: Alu elements as regulators of gene expression. Nucleic Acids Res 34: 5491-5497, 2006.

47. Mätlik K, Redik K and Speek M: L1 antisense promoter drives tissue-specific transcription of human genes. J Biomed Biotechnol 2006: 71753, 2006.

48. Jurka J, Kohany O, Pavlicek A, Kapitonov VV and Jurka MV: Duplication, coclustering, and selection of human Alu retrotransposons. Proc Natl Acad Sci USA 101: 1268-1272, 2004

49. Yao S, Ireland SJ, Bee A, Beesley C, Forootan SS, Dodson A, Dickinson T, Gerard P, Lian LY, Risk JM, et al: Splice variant PRKC- $\zeta(-\mathrm{PrC})$ is a novel biomarker of human prostate cancer. $\mathrm{Br}$ J Cancer 107: 388-399, 2012.

50. Szpakowski S, Sun X, Lage JM, Dyer A, Rubinstein J, Kowalski D, Sasaki C, Costa J and Lizardi PM: Loss of epigenetic silencing in tumors preferentially affects primate-specific retroelements. Gene 448: 151-167, 2009

51. Polak P,KarlićR,Koren A,Thurman R,SandstromR,LawrenceMS, Reynolds A, Rynes E, Vlahoviček K, Stamatoyannopoulos JA, et al: Cell-of-origin chromatin organization shapes the mutational landscape of cancer. Nature 518: 360-364, 2015.

52. Ying J, Li H, Seng TJ, Langford C, Srivastava G, Tsao SW, Putti T, Murray P, Chan AT and Tao Q: Functional epigenetics identifies a protocadherin PCDH10 as a candidate tumor suppressor for nasopharyngeal, esophageal and multiple other carcinomas with frequent methylation. Oncogene 25: 1070-1080, 2006.

53. Hynes NE: Tyrosine kinase signalling in breast cancer. Breast Cancer Res 2: 154-157, 2000

54. Vorlová S, Rocco G, Lefave CV, Jodelka FM, Hess K, Hastings ML, Henke E and Cartegni L: Induction of antagonistic soluble decoy receptor tyrosine kinases by intronic polyA activation. Mol Cell 43: 927-939, 2011.

55. Holst F, Stahl PR, Ruiz C, Hellwinkel O, Jehan Z, Wendland M, Lebeau A, Terracciano L, Al-Kuraya K, Jänicke F, et al: Estrogen receptor alpha (ESR1) gene amplification is frequent in breast cancer. Nat Genet 39: 655-660, 2007.

56. Martin AJ, Grant A, Ashfield AM, Palmer CN, Baker L, Quinlan PR, Purdie CA, Thompson AM, Jordan LB and Berg JN: FGFR2 protein expression in breast cancer: Nuclear localisation and correlation with patient genotype. BMC Res Notes 4: 72, 2011.

57. Cha JY, Lambert QT, Reuther GW and Der CJ: Involvement of fibroblast growth factor receptor 2 isoform switching in mammary oncogenesis. Mol Cancer Res 6: 435-445, 2008.

58. Bates DO and Harper SJ: Therapeutic potential of inhibitory VEGF splice variants. Future Oncol 1: 467-473, 2005. 